\title{
Microgripper design and evaluation for automated $\mu$-wire assembly: a survey
}

\author{
H. Llewellyn-Evans ${ }^{1}$ C. A. Griffiths ${ }^{1}$ (1) - A. Fahmy ${ }^{1}$
}

Received: 27 August 2019/Accepted: 26 December 2019/Published online: 23 January 2020

(C) The Author(s) 2020

\begin{abstract}
Microgrippers are commonly used for micromanipulation of micro-objects from 1 to $100 \mu \mathrm{m}$ and attain features of reliable accuracy, low cost, wide jaw aperture and variable applied force. This paper aim is to review the design of different microgrippers which can manipulate and assemble $\mu$-wire to PCB connectors. A review was conducted on microgrippers' technologies, comparing fundamental components of structure and actuators' types, which determined the most suitable design for the required micromanipulation task. Various microgrippers' design was explored to examine the suitability and the execution of requirements needed for successful micromanipulation.
\end{abstract}

\section{Introduction}

In recent decades, demands for micromanipulation have increased in industrial assembly fields due to the nature of technology progressing to micro scales components assembly. Micromanipulation is the study of positioning micro-objects ranging from 1 to $100 \mu \mathrm{m}$ in size. These micro-sizes can be a challenge task to manoeuvre without the use of micromanipulator tools due to additional attractive forces, viewing difficulties, high precision, and accuracy requirements (Adriaens et al. 2000; Yuan et al. 2015; Duc et al. 2006). To improve product quality and lead times, the use of robotic automation is being investigated to support micromanipulation equipment. There are two major techniques used for micromanipulation known as contact and non-contact methods, examples of these technologies are the electromagnetic fields, piezoelectric materials, electrostatic forces, electro thermal effect, shape memory alloys, magnetic guiding systems, and optical technologies (Nikoobin and Niaki 2012). These technologies can be utilised in the form of probes, needles, grippers and contactless devices. These methods have various advantages and disadvantages and are all at different stages of continuous development within research domain. The following section will discuss and review these methods.

C. A. Griffiths

c.a.griffiths@swansea.ac.uk

1 College of Engineering, Swansea University, Swansea SA2 8PP, UK

\section{Microgrippers}

Microgrippers are commonly developed in order to manipulate micro-objects, such as microwires and microspheres. It has been stated that microgrippers are often the most suggested technology in use for micromanipulation, often due to their reliable accuracy, low cost, wide jaw aperture, and variable applied force (Nikoobin and Niaki 2012). All microgrippers are developed with different structure designs and different actuator types to control the gripper. A standard microgripper normally consists of a pair of gripping jaws, an actuator mechanism, and an amplification method (Long et al. 2017). Microgrippers have two major classifications based on their structure; cantilever and flexible hinge, these will be evaluated initially below.

\subsection{Structure types of microgrippers}

There are two different groups of structural designs for a microgripper; cantilever or flexible hinge. Both of these methods are used to ensure that the arms of the grippers are capable of opening and reverting back to its original positions. The structure suitability is dependent on the shape and size of the object to be grasped. The design of cantilever microgrippers are built around each arm being fixed at the base, whilst a form of actuator forces the material to bend apart or together, causing the structure to flex (Haddab et al. 2000; Suzuki 1994; Du et al. 1999; Jain et al. 2015; Giouroudi et al. 2008). This form of structure 
results in a mechanical stress being distributed throughout the material as a force is applied to it. It is then the elastic potential energy within the material of the cantilever that ensures that the structure springs back to its original position. The flexible hinge structured microgripper are often more advanced and contain complex designs. They are commonly developed using computer modelling and mathematical analysis methods (Zubir et al. 2009). The design of the majority of flexible hinge microgrippers available are described as monolithic due to being manufactured out of a single material and are often produced using microfabrication techniques (Zubir et al. 2009). This is one advantage over cantilever structures as they are capable of being scaled down to a size of $33 \mathrm{~mm} \times 9$ $\mathrm{mm} \times 3 \mathrm{~mm}$ and are capable of manipulation smaller sized objects, whereas cantilever structures can only be used to manipulate larger objects however they may apply excessive force to the object (Yang and Xu 2017; Kawamoto 2009). The most important element of this type of gripper are the flexible hinges themselves. These sections of the structure are comprised of thin sections of the material and hence the most susceptible to bending. These features ensure that the stresses of the structure are concentrated within certain point whilst the other sections of the structure remain rigid. This can be advantageous in various aspects of the microgripper use.

Various shapes of hinges have been studied in previous literature. Circular notch hinges are an increasingly popular design of flexible hinge as studied in previous literature (Liang et al. 2018; Wang et al. 2013a, 2015; Kyung et al. 2008; Nah and Zhong 2007; Shi et al. 2018; Keoschkerjan and Wurmus 2002). This type of flexible hinge contains many advantages including being capable of achieving a large defamation prior to exceeding the tensile yield limit of the material being used. The use of a circular hinge also ensures a more precise and constant point of rotation along its axis throughout the deflection process (Keoschkerjan and Wurmus 2002). The flexible circular hinges are designed to closely mimic ideal hinges thus creating maximum displacement at the tips due to the minimum stiffness of each hinge. This hinge design also ensures high position accuracy and repeatability of the movement of the jaws of the microgripper due to the circular structure of the hinges.

Another common shape is flexible leaf hinge which is capable of producing large displacements of the jaw tip, along with a reduced experienced stress along each hinge due to the larger area of where the stress is dispersed. However, due to the lack of circular rotation, the accuracy of the system decreases (Qingsong 2015; Beyeler et al. 2007; Qu et al. 2017). The advantages of the flexible leaf hinge do not however justify its use as the most important required feature is the accuracy. There are differences between the operating jaw angles of each structure type. Firstly, as a force is applied to the arms of a cantilever material the length of it bends, therefore the angle of each jaw will change whilst open and closed. In this situation, this angle change may be problematic, especially when attempting to manipulate objects with curved edges such as microwire or microspheres. The flat edges of a two-armed gripper may not be parallel to each other when closed around the object, causing an inadvertent force applied to it. This results in an insecure grasp of the object and may lead to its unintentional release. On the other hand, flexible hinge microgrippers are often a monolithic structure and are designed to ensure that the jaws remain parallel during the gripping process (Zubir et al. 2009). This is beneficial when attempting to manipulate a wide range of object shapes and sizes. A commonly used structure design to ensure this parallel movement is described as a parallelogram shaped flexible hinge structure. It often comprises of four flexible hinges and two rigid beams per arm. As the arm is actuated, the beams remain parallel and hence ensure that the jaws remain parallel. The flexible hinge designs have the advantage of a greater position repeatability and accuracy. Various types of monolithic flexible hinge grippers have been studied along with the different configurations available to produce a flexible hinge with a large jaw aperture (Nah and Zhong 2007; Beyeler et al. 2007; Qu et al. 2017; Cauchi et al. 2018). Prior research has suggested to employ the corner fillet hinge design to enable the maximum change in jaw tip displacement (Zubir et al. 2009). The advantages and disadvantages of both structures are displayed in Table 1. Along with the chosen structure of a microgripper, it is essential to consider a suitable technology which is used to apply force to the gripper to enable it to open and close. These are referred to as actuators and are further analysed in the next paragraph.

\subsection{Actuator types of microgrippers}

When developing a microgripper, the choice of actuator remains an important part of the process. The actuator is the component of the microgripper which applies force to the structure to enable the jaws to open and close. Throughout the development of microgrippers, various technologies have been trialled to find the most suitable type of actuator, such technologies include; piezoelectric (Fig. 1) electromagnetic (Fig. 2), electrostatic (Fig. 3), electro-thermal (Fig. 4), and shape memory alloys (SMA) (Fig. 5). A literature report published an algorithm which described the design process of a microgripper (Nikoobin and Niaki 2012). Within this report, the variables that were capable of affecting the design requirements of a microgripper were highlighted, such as jaw aperture, shape of jaw, and actuator type (Nikoobin and 
Table 1 Advantages and disadvantages of different microgripper structures

\begin{tabular}{|c|c|c|}
\hline $\begin{array}{l}\text { Structure } \\
\text { type }\end{array}$ & Advantage & Disadvantage \\
\hline Cantilever & $\begin{array}{l}\text { Easy to fabricate } \\
\text { Larger jaw tip displacement with larger size of } \\
\text { gripper } \\
\text { Suitable to utilize with various actuator } \\
\text { technologies } \\
\text { Typically, large jaw aperture size }\end{array}$ & $\begin{array}{l}\text { Difficult to scale down to lower micro-scale } \\
\text { Jaw tips not consistently parallel } \\
\text { Increase in length of arms results in increase in jaw aperture size, but decrease in } \\
\text { applied force }\end{array}$ \\
\hline $\begin{array}{c}\text { Flexible } \\
\text { hinge }\end{array}$ & $\begin{array}{l}\text { Can be scaled down to } 33 \mathrm{~mm} \times 9 \mathrm{~mm} \\
\text { Often designed to ensure consistently parallel } \\
\text { jaw tip } \\
\text { Grasp a wide range of object sizes } \\
\text { High position accuracy and repeatability } \\
\text { Suitable to utilize with various actuator } \\
\text { technologies }\end{array}$ & $\begin{array}{l}\text { Complex design } \\
\text { Often requires electrical discharge machine to manufacture } \\
\text { Fragile at smaller scale }\end{array}$ \\
\hline
\end{tabular}

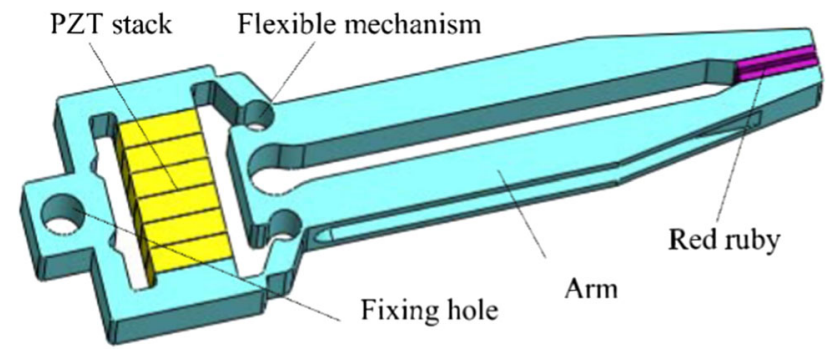

Fig. 1 Image of a monolithic microgripper actuated using stack piezoelectric material, developed by Haddab et al. (2000)

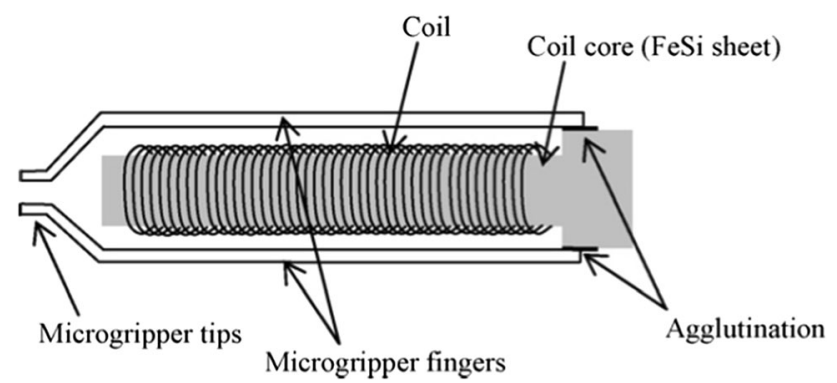

Fig. 2 Image of a cantilever style microgripper actuated using an electromagnet, developed by (Giouroudi et al. 2008)

Niaki 2012). A state of the art review was published afterwards, which describes the use of different actuator types used within microgrippers (Jia and Xu 2013). Discoveries from the paper and other research are explained in the next five sections of this review. The types of actuators will be evaluated by comparing the advantages and disadvantages for each (Table 2).

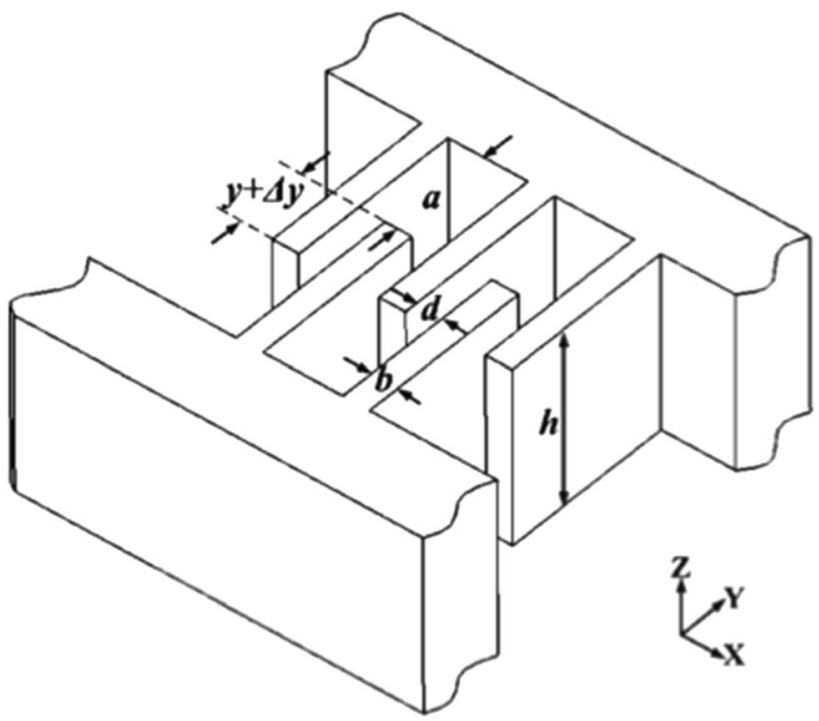

Fig. 3 Electrostatic comb structure developed by Chen et al. (2009)

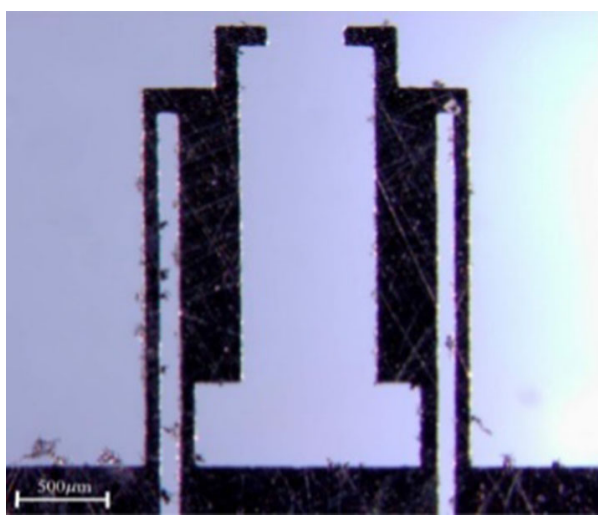

Fig. 4 Electro-thermal U-shaped microgripper developed by Kolahdoozan et al. (2017) 


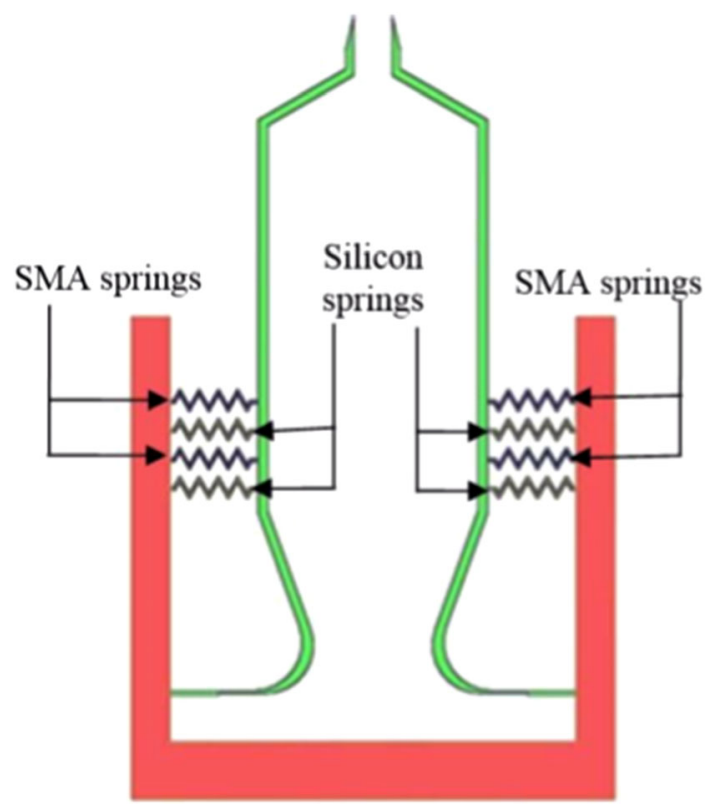

Fig. 5 Shape memory alloy actuated cantilever microgripper developed by Munasinghe et al. (2016)

\subsubsection{Electromagnetic microgrippers}

Electromagnetic actuated microgrippers utilize electromagnets to open and close the jaw of the gripper. This type of microgripper is often utilized in the form of a cantilever style gripper as presented in Kim et al. (2005). The most common assembly of this actuator type is to place the electromagnet in the centre of two magnetic arms and jaws. Electrical current is conducted through the electromagnet and as it is increased, the magnetic arms are attracted towards it and the aperture size of the gripper tips decreases. Development and experimental trials have been carried out on this type of gripper. An electromagnetically actuated microgripper was developed that is capable of producing a maximum jaw gap of $250 \mu \mathrm{m}$ (Liaw et al. 2008). Trials of the gripper consisted of testing the grasping technique on a $50 \mu \mathrm{m}$ metal wire and a $125 \mu \mathrm{m}$ glass fibre. Manipulation of both objects were successfully gripped without errors in release or accuracy. The gripping force of the system was adjustable with an alteration of the electromagnet current, producing a maximum gripping force of $130 \mu \mathrm{N}$ (Liaw et al. 2008). However, concerns were noted about this system regarding to heating problems. While the microgripper was in operation its metallic components, manufactured using cold laser cutting, were noticed to increase in temperature from 27 to $38{ }^{\circ} \mathrm{C}$ over the course of a half hour where the length of the gripper arm increased by approximately $0.1 \mu \mathrm{m} /{ }^{\circ} \mathrm{C}$ (Liaw et al. 2008). This causes problems over time as the position and accuracy of the gripper may become unknown and will produce errors during the manipulation process. A similar
Table 2 Comparison of the main advantages and disadvantages of different actuator types collaborated from the literature above

\begin{tabular}{|c|c|c|}
\hline Actuator type & Advantages & Disadvantages \\
\hline Electromagnetic & $\begin{array}{l}\text { Large jaw displacement } \\
\text { Fast response } \\
\text { Linear response }\end{array}$ & $\begin{array}{l}\text { Large components required } \\
\text { Difficult to scale down } \\
\text { High operating temperature } \\
\text { Difficult to fabricate } \\
\text { Impacted by external magnetic fields }\end{array}$ \\
\hline Piezoelectric & $\begin{array}{l}\text { Large applied force } \\
\text { Large power to weight ratio } \\
\text { High displacement accuracy } \\
\text { Low energy usage } \\
\text { Predictable displacement } \\
\text { Fast response }\end{array}$ & $\begin{array}{l}\text { Low displacement } \\
\text { Hysteresis error }\end{array}$ \\
\hline Electrostatic & $\begin{array}{l}\text { Fast frequency response } \\
\text { Low energy usage } \\
\text { No hysteresis error }\end{array}$ & $\begin{array}{l}\text { Complex circuitry } \\
\text { High voltage } \\
\text { Large structure sizes } \\
\text { Low maximum gripping force }\end{array}$ \\
\hline Electro-thermal & $\begin{array}{l}\text { Large jaw tip displacement } \\
\text { Low voltage required }\end{array}$ & $\begin{array}{l}\text { High operating temperature } \\
\text { Slow time response } \\
\text { Non-linear response }\end{array}$ \\
\hline Shape memory alloy & $\begin{array}{l}\text { Low energy usage } \\
\text { High jaw displacement } \\
\text { High gripping force }\end{array}$ & $\begin{array}{l}\text { High hysteresis error } \\
\text { Large energy usage } \\
\text { Slow response time }\end{array}$ \\
\hline
\end{tabular}


gripper was developed with the intention of becoming an automated system for the purpose of manipulating a microwire (Ruiz et al. 2018). The gripper jaw had a cantilever structure using electromagnetic actuator. The gripper system was developed in order to manipulate a 50-70 $\mu \mathrm{m}$ diameter copper wire and move it to a desired position (Ruiz et al. 2018). The research trialled various arm lengths and jaw angles of microgripper and recognised the disadvantages of using a long tip as it reduces the clamping force available to grip the wire (Ruiz et al. 2018). Further experiments were carried out using different weight of objects at different orientations. The results concluded the microgripper's capability of manipulating the copper wire as required. Despite these successes, one report claims that producing a microgripper with an electromagnetic actuator is not preferable due to the complexity of the structure and the negative interference from external electromagnetic fields (Haddab et al. 2000). An additional disadvantage was that these types of microgrippers are often heavier than others due to the components required and may slow down the manoeuvring process and reduce the systems precision (Haddab et al. 2000). These actuator types are agreed to be able to produce a large jaw movement and gripper force which is ideal for larger object. However, due to the structure and components required it is difficult to scale down and hence a limitation for micromanipulation (Kolahdoozan et al. 2017).

\subsubsection{Piezoelectric microgripper}

Piezoelectric materials are a type of material that is capable of changing its shape when an external electrical voltage is applied to it. This form of technology has recently been utilised to produce an actuator for use within microgrippers as shown in Wang et al. (2015), Liaw et al. (2008), Ruiz et al. (2018) and Conway and Kim (2004). These actuators have been researched for uses in many different industrial fields such as medicine, robotics, space exploration and semiconductor fabrication (Long et al. 2017; Zubir et al. 2009; Beyeler et al. 2007; Chen et al. 2009). Piezoelectric grippers have been proven to be a suitable end-effector type capable of precisely manipulating small objects (Rakotondrabe and Ivan 2011). When compared to other gripper technologies, piezoelectric gripper have advantages that include: compact design, light weight structure, low energy usage, unaffected by electromagnetic fields, predictable displacement, high precision, fast response time, large bandwidth, no slip effect, high gripping force and a high force to weight ratio (Xu 2014). Multi-layer piezoelectric materials are often used to produce a large jaw displacement and high force when compared to a single piece of piezo materials, therefore multi-layer stacking is used in the majority of piezoelectric actuators (Yang and $\mathrm{Xu}$ 2017; Wu and Xu 2018). Piezoelectric microgrippers have been proven to grip objects with a size as low as $15 \mu \mathrm{m}$ (Haddab et al. 2000). The work was focused on developing a system that was capable of accurately grasping and manipulating microwires (Haddab et al. 2000). The report stated that the gripper was able to achieve a maximum jaw aperture size of $170 \mu \mathrm{m}$ (Haddab et al. 2000). This size of jaw was suitable to grasp a large range of the wire diameters and micro-object sizes. The amplification ratio for the system was found to be 17.14 (Haddab et al. 2000). A three-stage, flexible hinge structure was designed to produce a large tip aperture (Wang et al. 2015). Each jaw of the gripper was capable of a $95 \mu \mathrm{m}$ displacement and had a 22.8 amplification value from the input displacement of the piezoelectric actuator (Wang et al. 2015). The gripper was tested by successfully gripping a $25.4 \mu \mathrm{m}$ diameter gold wire. The maximum jaw gap was $190 \mu \mathrm{m}$ while applying a voltage of $100 \mathrm{~V}$ (Kawamoto 2009). Moreover, using the piezoelectric material to produce a cantilever style microgripper was suggested to reduce the weight and complexity of the structure although it would also reduce the applied force (El-Sayed et al. 2013). Each cantilever was structured as a bimorph, by bonding two layers of piezoelectric materials together and therefore flexed due to the expansion of one material. The aperture size of the gripper tips was measured using a noncontact proximity sensor and results demonstrated that the gripper was capable of handling an object with a width of $50 \mu \mathrm{m}$ whilst the tip deflection reached a value of $520 \mu \mathrm{m}$ (El-Sayed et al. 2013). Another similar gripper fabricated from an aluminium plate and capable of ensuring that the system had high precision and also that the jaws remain parallel by using the parallelogram flexible hinge structure. Through practical experimentation, it was established that the gripper had an amplification of 3.68 and the jaw aperture was able to reach $100 \mu \mathrm{m}$ (Zubir et al. 2009). Wang et al., developed a monolithic piezoelectrically driven gripper which embedded a force and tip displacement sensor to supply feedback (Wang et al. 2013a). Each tip was able to move a maximum distance of $18 \mu \mathrm{m}$ when a voltage of $200 \mathrm{~V}$ is applied (Wang et al. 2013a). The coarse displacement of the jaw gripper is altered by adjusting a screw attached to the gripper (Wang et al. 2013a; Nah and Zhong 2007). The amplification of the gripper was measured to be around 16 (Wang et al. 2013a). The gripper design created the ability to move the jaws parallel to each other whilst achieving a large jaw aperture of at least $230 \mu \mathrm{m}$ (Wang et al. 2013a). The practicality of this microgripper was proven by grasping an optical fibre of this diameter (Wang et al. 2013a). One reported stated that the researchers successfully produced a flexible hinge style gripper that was capable of gasping and releasing 
object of a size range between 100 and $800 \mu \mathrm{m}$, which is a very large range compared to other grippers (Nah and Zhong 2007). However, this is due to the use of a preadjusting system and the microgripper had a maximum jaw tip displacement of $170 \mu \mathrm{m}$. The gripper with a monolithic design, had an amplification value of 3 and was designed to ensure that the jaws move in parallel to each other (Nah and Zhong 2007). The gripper was capable of grasping and releasing a $500 \mu \mathrm{m}$ diameter Teflon wire (Nah and Zhong 2007). Furthermore, it was also detailed that the microgripper had the potential to be scaled down further, making it more suitable to manipulate objects with a size less than $100 \mu \mathrm{m}$, but this theory will need to be further proved experimentally (Nah and Zhong 2007). Manipulating object as small as $10 \mu \mathrm{m}$ have be proven to be achievable through manipulating a $10 \mu \mathrm{m}$ diameter polystyrene ball and a $100 \mu \mathrm{m}$ diameter human hair proving that this design of microgripper is capable of grasping, not only cylindrical, but also spherical micro-objects of a very small size (Shi et al. 2018). A compliant microgripper capable of producing a jaw gap of $280 \mu \mathrm{m}$ was developed in $\mathrm{Xu}$ (2014, 2018). The initial jaw gap of the gripper has the potential to be adjusted and was therefore experimentally capable of manipulating $300 \mu \mathrm{m}$ diameter copper wire. The gripper could apply a force of around $20 \mathrm{mN}$ to an object (Xu 2018). In the majority of reported work, it is displayed that as the jaw gap decreases, the force applied by the jaws also decreases. However, one researcher developed a piezoelectric actuated microgripper that was able to apply a constant force to an object ( $\mathrm{Xu}$ 2014). The microgripper was able to apply the constant force by use of a passive stiffness mechanical structure which is triggered when the desired force on the object is reached ( $\mathrm{Xu}$ 2018). The fabricated microgripper was able to produce a jaw aperture of $220 \mu \mathrm{m}$ and produce a maximum of $530 \mathrm{mN}$ of force on an object (Xu 2018). A recently published paper describes the design of a monolithic gripper that utilizes the movement of only one gripper jaw (Wang et al. 2015). This piezoelectric actuated microgripper has been developed in this manner to increase the precision of the gripper. When a conventional two moving jaw microgripper grasps hold of a micro-object, the jaws of the gripper often dis-align from a central position and thus effect the consistence and accuracy of the system (Liang et al. 2018). The single movable jaw structure comprises of a moveable jaw and a fixed jaw. During the gripping process the micro-object will be held by both jaws, however the fixed jaw will remain in a constant position before and after the process and hence is a relatable constant point of the jaw (Liang et al. 2018). The microgripper also comprises of three different amplification systems from the piezoelectric material to the gripper jaws, which converts a small displacement from the material to a large jaw tip displacement of $75 \mu \mathrm{m}$ (Liang et al. 2018). Another survey reviewed a large quantity of various microgripper actuators and concluded that the piezoelectric actuated microgrippers studied were capable of producing jaw displacements between 16 and $8800 \mu \mathrm{m}$ while the applied voltage ranged from 0 to $700 \mathrm{~V}$ for different microgrippers (Dochshanov et al. 2017). The force from the tips varied from $1 \mu \mathrm{N}$ to $1.87 \mathrm{~N}$. And the amplification factor of the studied systems ranged between 2.85 and 50 (Dochshanov et al. 2017). This displays that piezoelectrically actuated microgrippers can be used to manipulate a wide range of object sizes. Throughout the research of thistype of technology, various limitations have been discovered including: hysteresis properties of the material, amplification discrepancies of the jaw aperture and inaccurate position placement of jaws (Shi et al. 2018; Beyeler et al. 2007; Qin et al. 2013; Grossard et al. 2009). One report presented the development of a monolithic piezoelectric gripper which had a maximum applied voltage of $150 \mathrm{~V}$ and a change in jaw tip position of $65 \mu \mathrm{m}$ (Shi et al. 2018). These researchers noticed that the two jaw arms did not display the same displacement and stated that this could have been due to fabrication variation or incorrect alignment of the piezoelectric material (Shi et al. 2018). Another researcher declared that any fabrication inaccuracies such as this must be reduced to ensure that the microgripper jaws achieve a high accuracy (Ruiz et al. 2018). Limitations were also found in another survey where it was found that using a piezoelectric actuator, the jaw position movements were lower in comparison to other actuator types and a hysteresis issue also noted ( $\mathrm{Jia}$ and $\mathrm{Xu}$ 2013). Another report produced a mathematical model that described the deflection and force values of a piezoelectric actuator (Grossard et al. 2009). They also proved the model experimentally by developing a microgripper with this actuator. The tip displacement of the microgripper prototype was said to be $1.5 \mathrm{~mm}$ with a force of $0.203 \mathrm{~N}$, where the maximum applied voltage was $60 \mathrm{~V}$ (Grossard et al. 2009). It was also discovered that a hysteresis error in the tip of the gripper occurred causing the tips of the gripper to follow different paths whilst opening and closing. This error was successfully reduced by controlling the voltage with a proportional derivative controller which reduced the error of the path from 0.2 to $0.02 \mathrm{~mm}$ (Grossard et al. 2009). The same researchers continued their study in 2015 and trialled the microgripper to pick up a $1 \mathrm{~mm}$ diameter pin and place it into a hole (Jain et al. 2015). The hysteresis error was again studied and a deflection error of $116 \mu \mathrm{m}$ was produced when comparing the opening and closing paths of the gripper (Jain et al. 2015). The proportional-derivative controller along with a laser position sensor was able to reduce this error and resulted in the successfully placement of the pin (Jain et al. 2015). 
Table 3 Various researched microgripper types with a comparison of their main characteristics

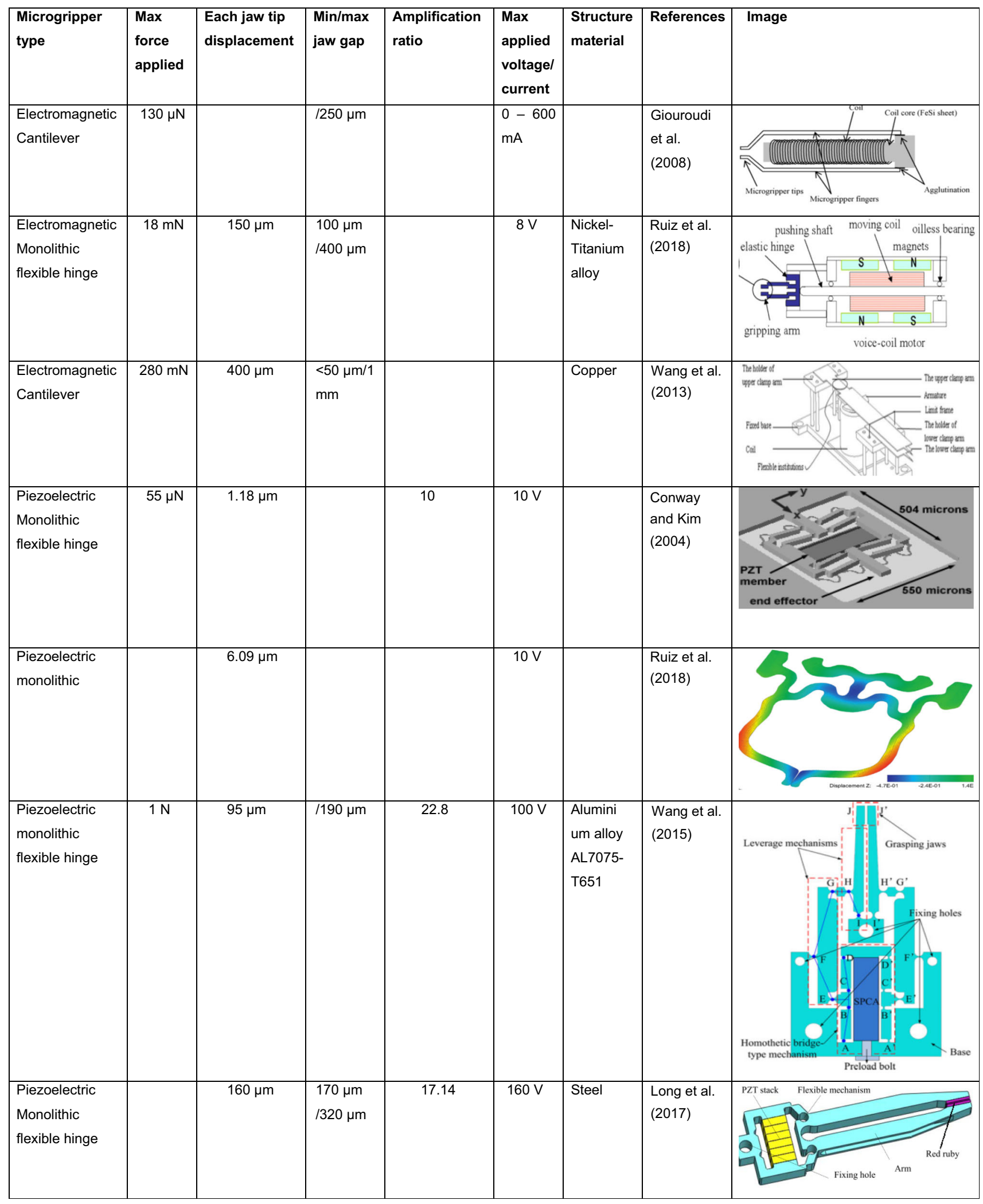


Table 3 continued

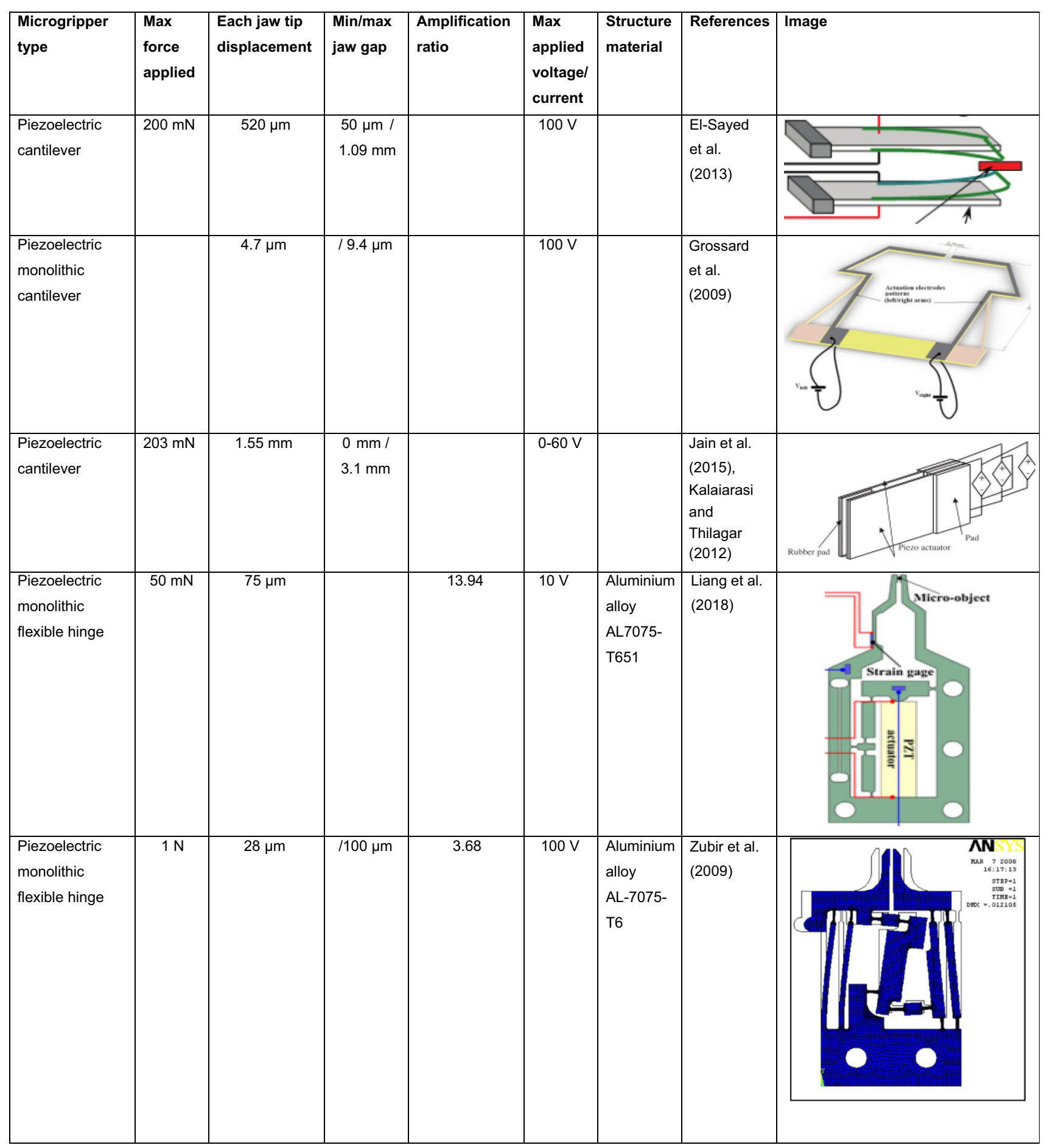


Table 3 continued

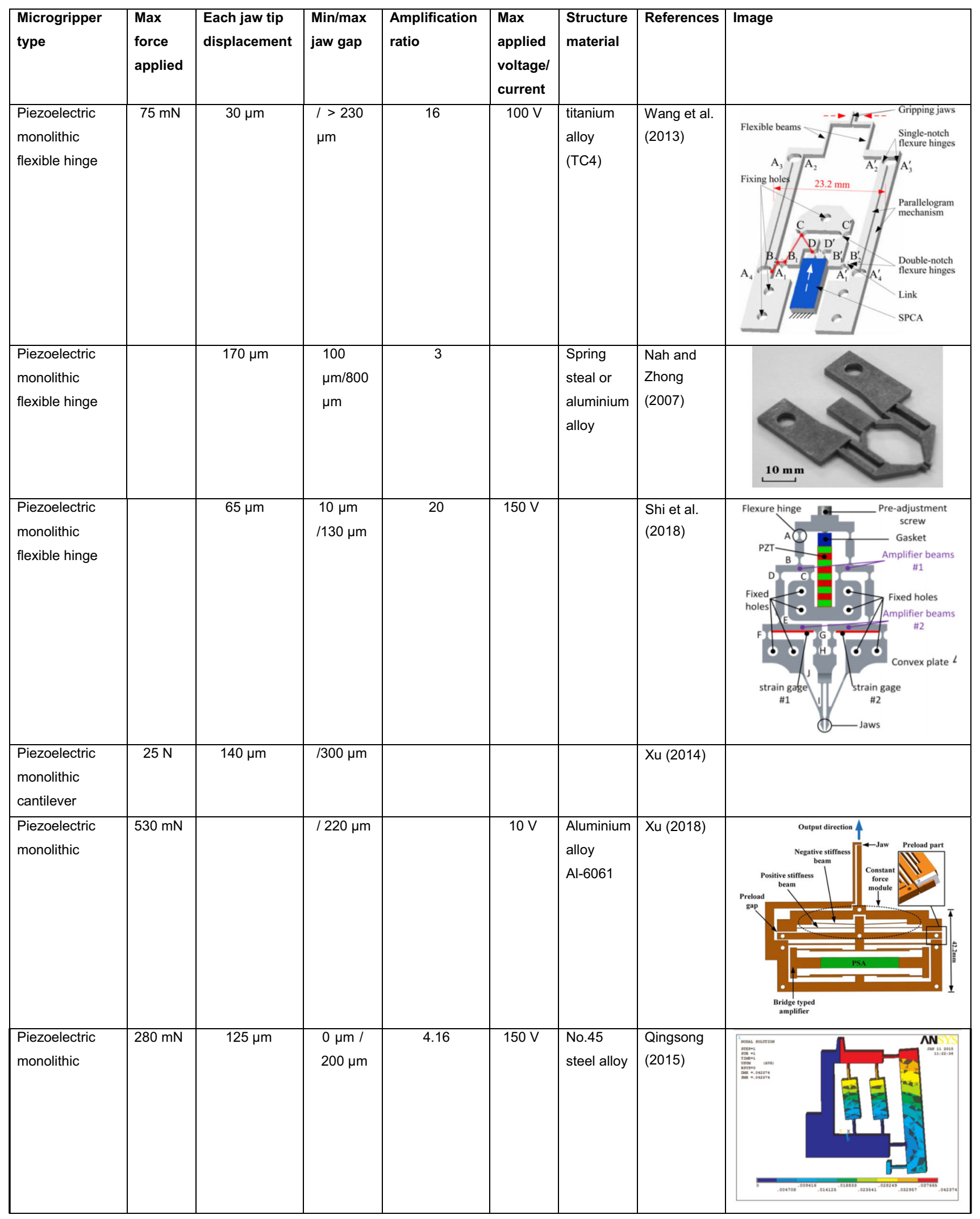


Table 3 continued

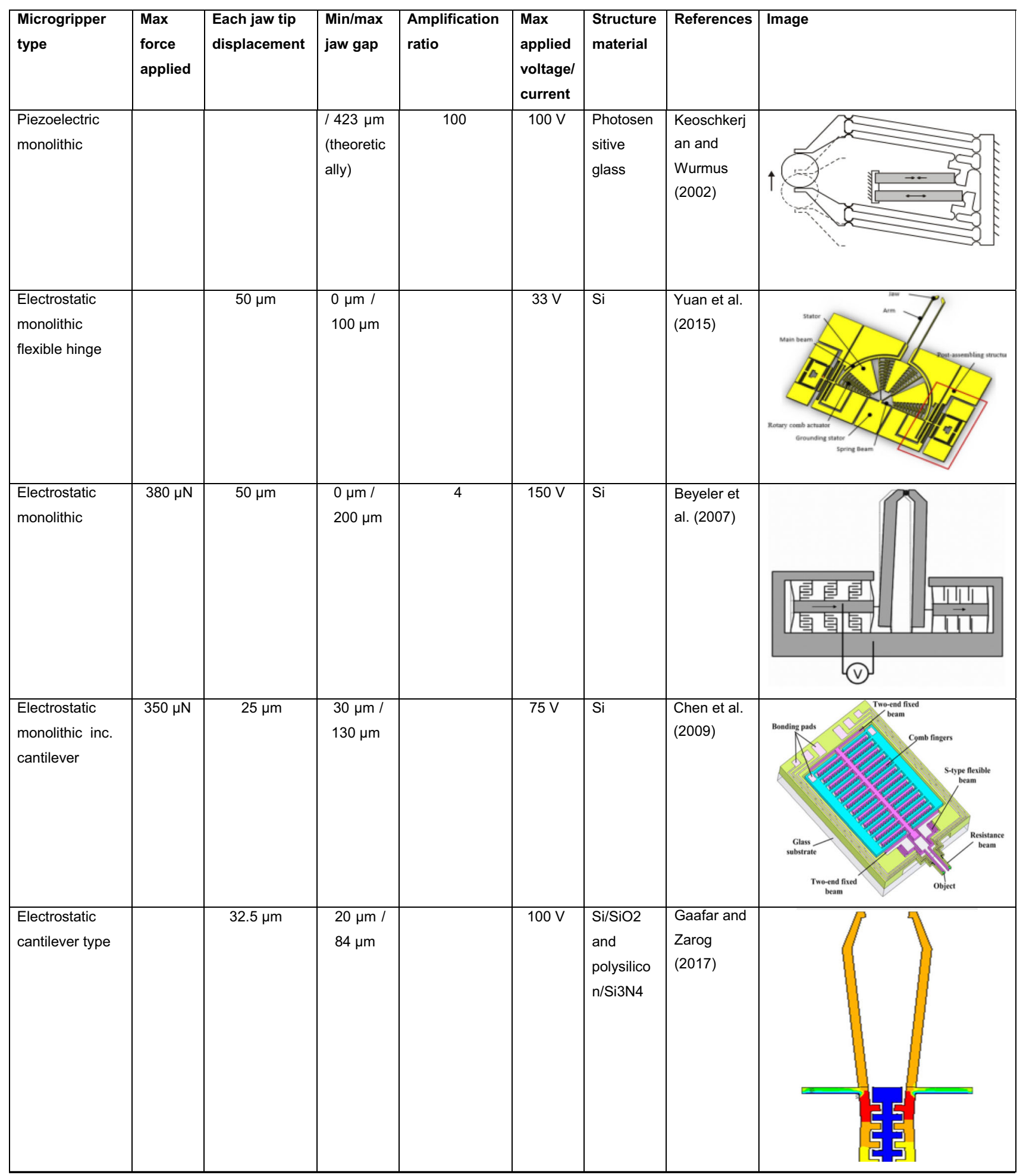


Table 3 continued

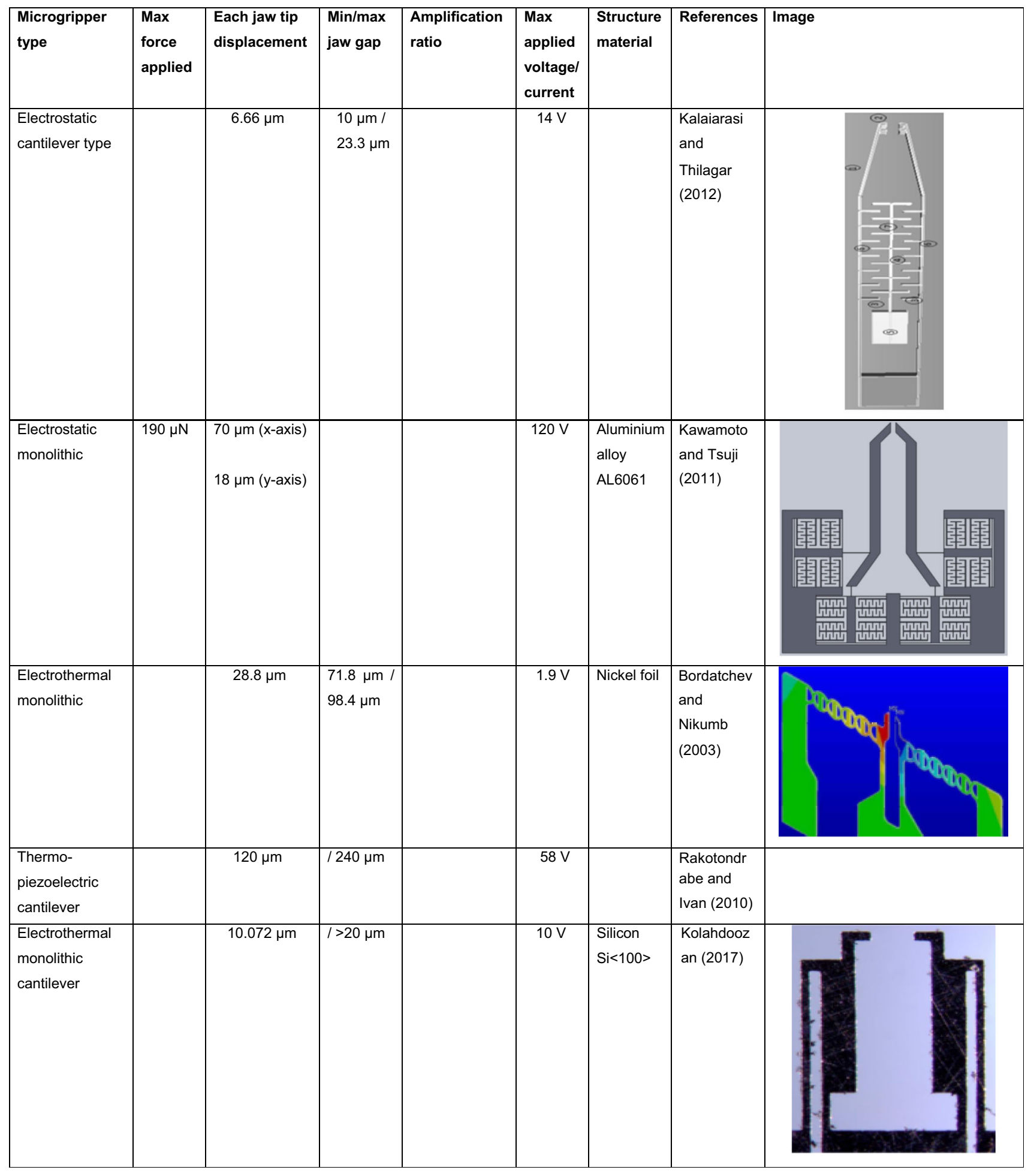


Table 3 continued

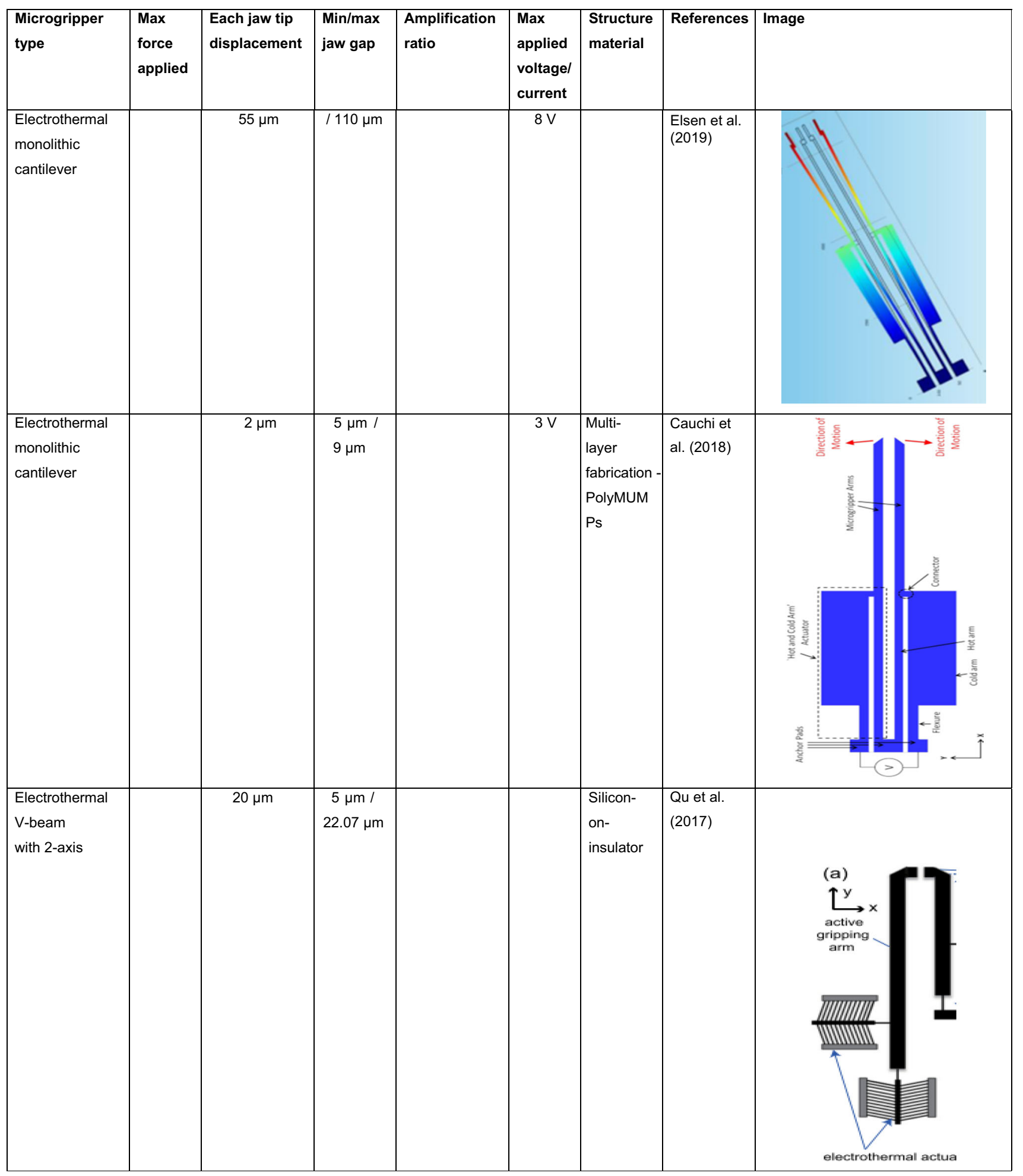


Table 3 continued

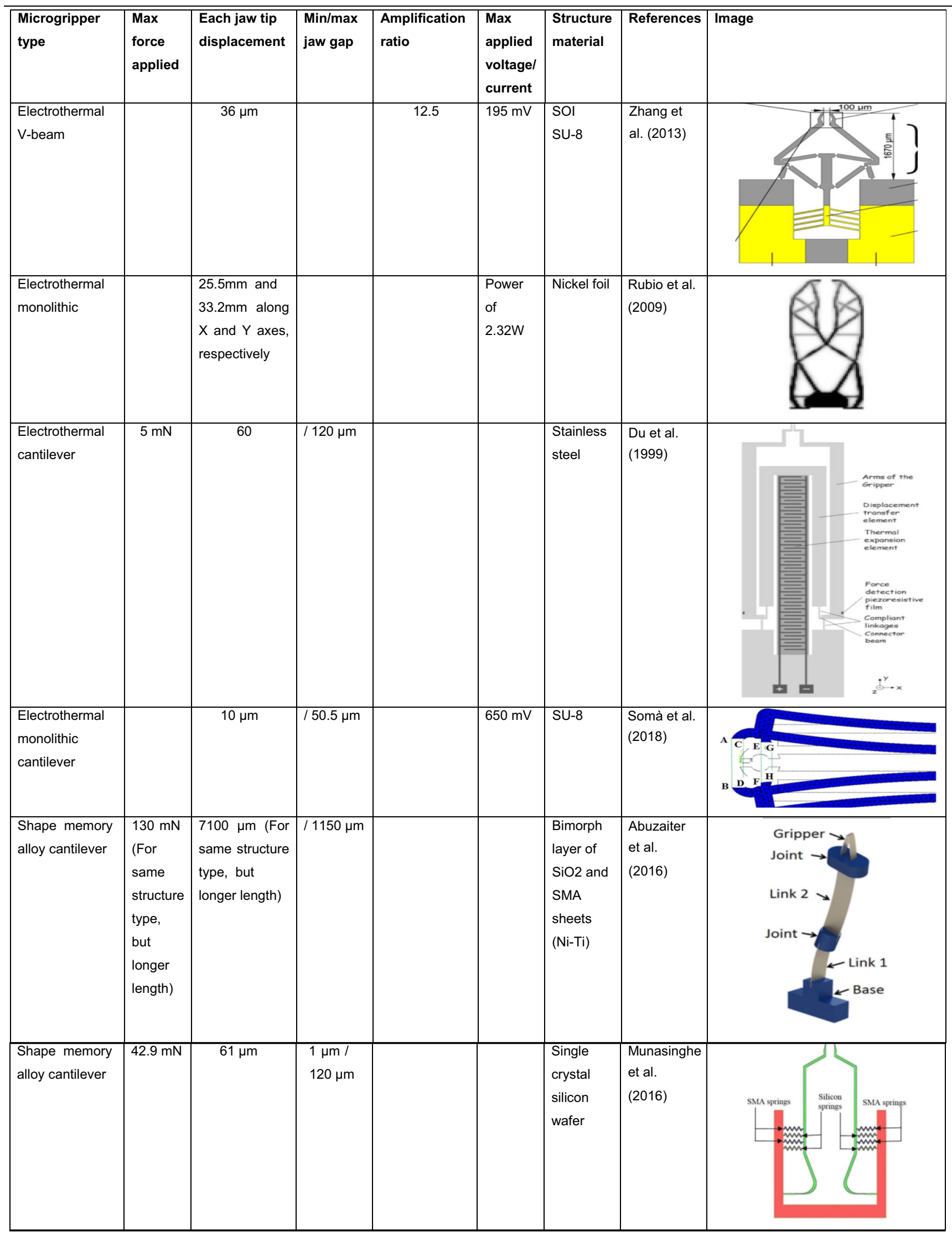


Table 3 continued

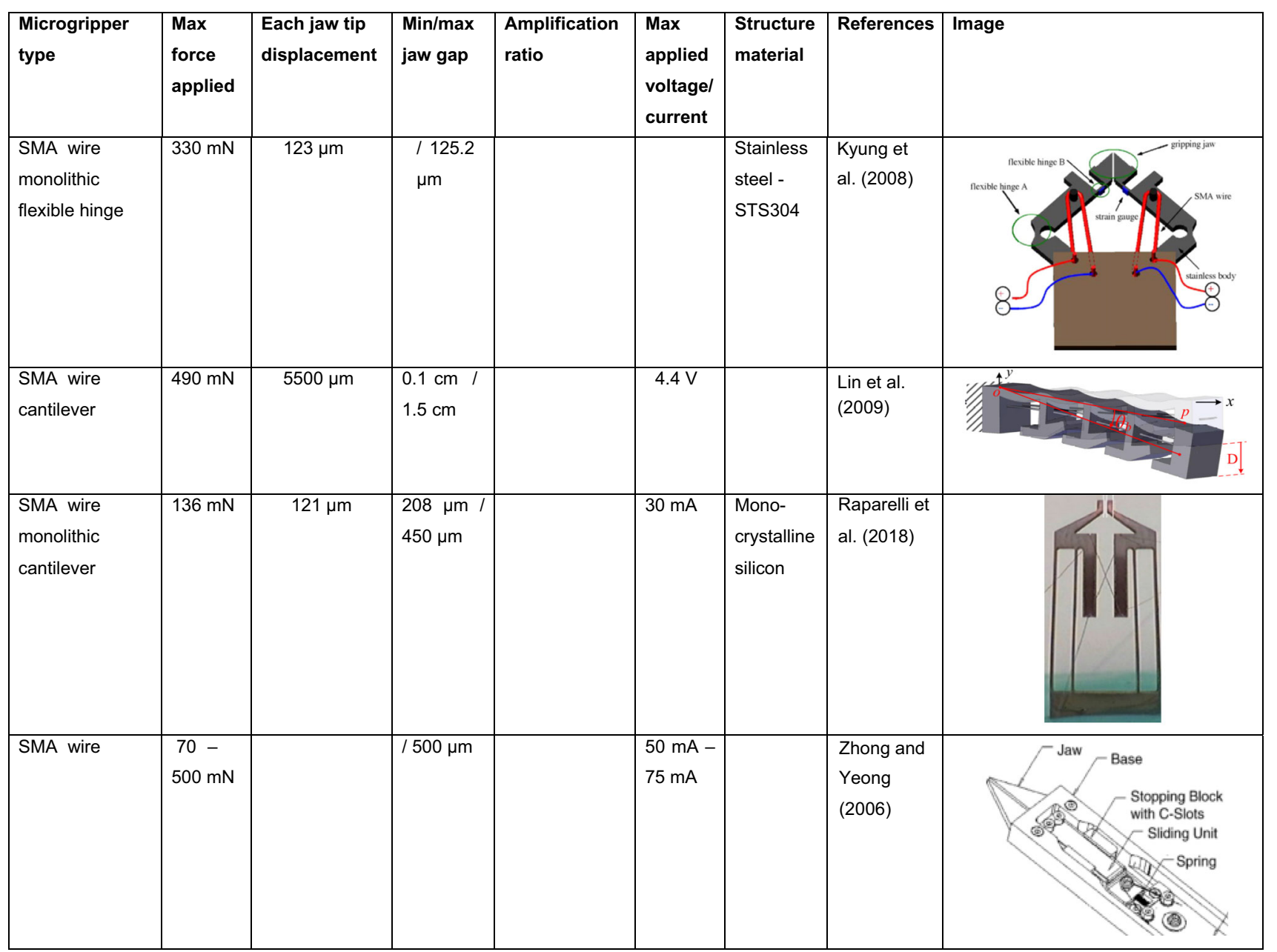

\subsubsection{Electrostatic microgripper}

Electrostatically actuated microgrippers are utilised by applying a positive and negative voltage to two elements of the microgripper which then attract or repel each other due to the electrostatic force created. The structure of these microgrippers are frequently found in literature to be in a comb formation, which consists of two interlocking combs (Kalaiarasi and Thilagar 2012). As a voltage is applied to the combs, an electrostatic charge is produced, and the combs either attract or repel. This structure is integrated with a set of jaw, which enables them to open or close. The structure is easy to fabricate, requires a low voltage, can produce a large tip deflection (e.g. $70 \mu \mathrm{m}$, Table 3 ) and has a faster response to a change of voltage in comparison to other methods, such as electro-thermal (Yang and $\mathrm{Xu}$ 2017). In the 2013 review by Jai and $\mathrm{Xu}$, it was described that the benefits of using an electrostatically actuated microgripper are that it can obtain a large jaw aperture change whilst producing no hysteresis effects which produces a predictable response (Jia and $\mathrm{Xu}$ 2013). Another report researched electrostatically controlled microgrippers with the capability of manipulating a micro-object from 0 to $100 \mu \mathrm{m}$ between the voltages of 0 and $33 \mathrm{~V}$ respectively (Yuan et al. 2015). This report developed a novel mechanism for the gripper to self-lock whilst operating, which enabled the gripper to hold an object for a long time without the need to apply voltage during these periods (Yuan et al. 2015). The benefit of this is to ensure that the gripper does not caused unnecessary stress or damage on the object and further reduces the amount of energy used by the microgrippers (Yuan et al. 2015). The system was trialled by successfully holding a metal wire with a diameter of $40.6 \mu \mathrm{m}$ (Yuan et al. 2015). Electrostatically 
actuated grippers have been integrated with jaws where the applied force can be precisely controlled (Chen et al. 2009). This gripper was additionally developed to have three tweezers within the gripper to enable the system to grasp a wide range of object (Chen et al. 2009). The grippers themselves were controlled using electrostatic forces, the force sensors utilize piezoelectric materials to detect the force that is being applied to the object (Chen et al. 2009). Each arm tip is capable of a $25 \mu \mathrm{m}$ deflection although the system as a whole can manipulate objects between 30 and $130 \mu \mathrm{m}$ (Chen et al. 2009). The gripper was trialled on a variety of sized polystyrene microspheres of sizes between 30 and $80 \mu \mathrm{m}$ (Chen et al. 2009). It was measured that a force of $350 \mu \mathrm{N}$ and $100 \mu \mathrm{N}$ were applied to the object, with the driving voltage of $75 \mathrm{~V}$ and $58 \mathrm{~V}$ respectively (Chen et al. 2009). In the medical industry, different types of piezoelectric actuated microgrippers have been developed and utilised. It was suggested that microtechnological devices such as microgrippers can be used to assist in minimally invasive surgery and other challenging scenarios regarding to technicality and small-scale sizes (Gaafar and Zarog 2017). One type of gripper developed in 2017 contained a comb structure described above and different types of materials were studied for use in the conducting and insulating components of the gripper (Gaafar and Zarog 2017). The applied voltage was of $100 \mathrm{~V}$ with the displacement of the two material types of $19.66 \mu \mathrm{m}$ and $32.5 \mu \mathrm{m}$, this highlights that the choice of material is an important factor to consider (Gaafar and Zarog 2017). Another form of electrostatically actuated comb driven microgripper was developed in 2012 where the researchers simulated the grippers with various shapes of combs (Kalaiarasi and Thilagar 2012). The trialled shapes included a square notch, a 2 stepped notch, small v-shaped notch and large v-notch. From the shapes suggested, the large v-shaped notch produced the greatest jaw tip displacement of $6.66 \mu \mathrm{m}$ and $21.25 \mu \mathrm{m}$ with voltages of $14 \mathrm{~V}$ and $25 \mathrm{~V}$ respectively (Kalaiarasi and Thilagar 2012). However, the jaw displacement of this microgripper was significantly less than other structures, therefore it should be noted that the applied voltage in this design is furthermore less compared to others, resulting in a decrease in energy consumption. Another survey stated that the electrostatic actuated microgrippers reviewed, showed various jaw displacement ranges between 2.5 and $275 \mu \mathrm{m}$, with an applied voltage range between 0 and $185 \mathrm{~V}$, a force from the jaws of $4 \mathrm{nN}$ to $2.5 \mathrm{mN}$ and an amplification factor between 4 and 5.9 (Verotti et al. 2017). The jaw displacement ranges of these electrostatically actuated microgrippers are able to achieve smaller jaw displacements compared to the piezoelectric actuated grippers as above. This suggests that electrostatic actuators are better suited to manipulate micro-objects within the range of
$1-100 \mu \mathrm{m}$ in compared to other microgripper actuator types. However, there are operational limitations such as requiring a high operating voltage to produce a high jaw displacement, unable to achieve high gripper forces and large structure sizes (Jia and $\mathrm{Xu} 2013$ ).

\subsubsection{Electro-thermal microgripper}

The method behind electro-thermal actuators is based on the phenomena that as current is passed through a conductor, it will cause it to increase heat and results in an expansion of the material. This is often utilized within microgrippers and is used to open and close its jaws. These microgripper types are often fabricated with a monolithic structure and usually created using the chip manufacturing process (Kolahdoozan et al. 2017; Wu and $\mathrm{Xu}$ 2018). It is also capable of producing cantilever structures using this method by utilizing bi-metallic strips. The advantages of using this form of actuator is the capability of producing a larger gripping force and jaw displacement while low voltages are applied (Jia and $\mathrm{Xu}$ 2013). With regards to materials used to manufacture the microgrippers, it has been stated that silicon, stainless steel and high grade aluminium alloys are common choices for electro-thermally actuated microgrippers (Nikoobin and Niaki 2012). Monolithic electro-thermal microgrippers often come in three structures: U, V and Z-shaped. The most common form is the $U$ shaped structure and is designed so that each arm comprises of two parallel, but separately insulated beams, only one of which is heated by an applied current, due to this, the tip of the arm flexes away from the heated stem (Yang and Xu 2017; Chronis et al. 2005; Zhang et al. 2013; Zhang et al. 2011). It has been stated that grippers of this structure are capable of producing a displacement of up to $262 \mu \mathrm{m}$ with an applied voltage of $1.94 \mathrm{~V}$ (Yang and Xu 2017). The V shaped structure contains a central component suspend from two thin lengths of material in a $\mathrm{V}$ shape (Yang and $\mathrm{Xu}$ 2017). As the material is heated, the central component will move a predictable distance. It has been stated that this structure is capable of achieving a movement of $173 \mu \mathrm{m}$ with an applied voltage of $1 \mathrm{~V}$ (Yang and $\mathrm{Xu}$ 2017). The $\mathrm{Z}$ structure actuator utilises the same method as used in the $\mathrm{V}$ shape structure however the two suspending materials are shaped in a Z-notch formation and produces a linear movement of the central component capable of moving it $80 \mu \mathrm{m}$ with an applied voltage of $6 \mathrm{~V}$ (Yang and $\mathrm{Xu}$ 2017). Another paper described the utilisation of the electro-thermal effect to actuate a novel design of microgripper which comprised a series of D-shaped loops placed consecutively between the actuator arms and the gripping tips (Bordatchev and Nikumb 2003). As a current was applied to the structure, the D-shaped loops would increase in temperature and hence expand, causing 
the jaw aperture to decrease. The microgripper was capable of producing a jaw aperture between 98.4 and $71.8 \mu \mathrm{m}$ with applied current of 0.32-0.84 A respectively, although the writers stated that a larger gap would be achievable by improving the gripper design, however it was not stated what improvement would be implemented. To incorporate the high range capabilities of an electro-thermal actuator, but also utilize the high speed and precision accuracy of a piezoelectric actuator, a hybrid actuator microgripper has been previously fabricated (Rakotondrabe and Ivan 2010). The structure of the arm used a dual layer cantilever comprising of a piezoelectric layer and a passive layer. When heat is applied to it, it is capable of deflecting distances higher than $100 \mu \mathrm{m}$ for each arm, resulting in a total jaw aperture of at least $200 \mu \mathrm{m}$. However, while actuated by the piezoelectric system, each arm was capable of deflecting a distance of approximately $15 \mu \mathrm{m}$. The system used the electro-thermal actuator to coarsely guide the cantilever tips to the object to be grasped, from there the piezoelectric actuator could finely adjusts the tips to hold the object. The disadvantages of the system is the complexity of having to provide a feedback system which incorporates data from both actuator types, however this was solved in the paper (Rakotondrabe and Ivan 2010). This report stated that electro-thermally actuated microgrippers produce a larger jaw displacement of around $55 \mu \mathrm{m}$ and large gripping force whilst using low voltages of 1-8 V (Elsen et al. 2019). Results from the report showed that the response of displacement to the applied voltage was exponential (Qin et al. 2013). This type of microgripper often produces a non-linear opening and closing whilst using high temperatures, therefore the design of the structure needs to be carefully considered to ensure that the desired gripping aperture can be reached (Jia and $\mathrm{Xu}$ 2013). However, in many applications a linear response may not be required during operation times, hence this limitation would not be an issue. One of the main limitations of electro-thermally actuated grippers is with regard to the amount of heat generated by the gripper in order to alter its jaw aperture size (Jia and Xu 2013). This is often undesired as it may result in exerting heat to the object that is being manipulated and may subsequently cause damage. One paper explains the development of a novel design of electro-thermal gripper that is based on a U-shaped style of microgripper (Fu et al. 2012). The report states that the design presented is less complex than other electro-thermally actuated structures and also states that the structure is capable of achieving predictable jaw movement with a certain applied voltage (Fu et al. 2012). The jaw displacement for the gripper was said to be $10.072 \mu \mathrm{m}$ while the voltage applied was between 1 and $10 \mathrm{~V}$ ( $\mathrm{Fu}$ et al. 2012). It was also stated that the maximum temperature of the arms reached a value of $224{ }^{\circ} \mathrm{C}$, although the temperature value at the tips was not able to be measured due to equipment limitation (Fu et al. 2012). The temperature of the tips must often be considered and measured during operation, as high temperature may cause damage to micro-objects during the manipulation process. An electrothermal actuated microgripper produced was capable of achieving motion along two axis, which was stated as being a first in research (Qu et al. 2017). The gripper also integrated a capacitive force detection system capable of measuring the amount of force applied to the gripper jaws $(\mathrm{Qu}$ et al. 2017). The researchers also noted that heat conducting along the tip may also cause micro-object damage (Qu et al. 2017). Within the medical industry, microgrippers have been designed to manipulate red blood cells. An electro-thermal microgripper developed was able to produce a jaw displacement of $9 \mu \mathrm{m}$, which was said to be the value desired to manipulate the blood cells (Cauchi et al. 2018). The difficulty with attempting to use an electro-thermally actuated microgripper to manipulate biological matter is that the heat produced by the gripper has the potential to cause damage to the subject. It is also important to ensure that the maximum temperature produced by the microgripper does not reach the limiting temperature values of the materials of the microgripper itself, hence causing inherent damage. The gripper designed in this report was based on a U-shaped structure. To ensure that heat did not conduct through the gripping arms, each included a structure comprised of a thin sheet of material, the width of the gripper, which contained a matrix of holes throughout in order to dissipate heat. A simulation of the structure showed that although the maximum temperature of the structure reached $267^{\circ} \mathrm{C}$, the tips of the gripper remained at room temperature, proving that this structure would not apply excess heat to the micro-object (Cauchi et al. 2018). A survey stated that after reviewing a vast amount of electromagnetically actuated microgrippers, the jaw displacement range are found to be between 1.2 and $260 \mu \mathrm{m}$, the applied voltage is between 0.1 and $90 \mathrm{~V}$, exerted force from jaws between $20 \mu \mathrm{N}$ and $135 \mathrm{mN}$ and amplification of 1.731-100 (Dochshanov et al. 2017).

\subsubsection{Shape memory alloy microgripper}

Shape memory alloys (SMA) can change their characteristic features when heat is applied. The material is capable of transforming its shape and size whilst at high temperatures and further returns to its original position when the heat is removed (Kawamoto 2009). This ability has been utilised for producing actuators for microgrippers as displayed in Kawamoto (2009). It has been shown that SMA actuated microgrippers are able to produce high jaw displacement values and gripping force. Although a delayed reaction is produced when voltages are applied in compare 
to other gripper types. One review has stated that using Nickel-Titanium material to create SMA actuated microgrippers has been proven to be very successful as it has the ability to produce a high gripping force and jaw tip displacement at temperatures around $60-80{ }^{\circ} \mathrm{C}(\mathrm{Fu}$ et al. 2012; Choudhary and Kaur 2016). A microgripper actuator review from 2012 revealed that SMA actuators are commonly studied due to the high energy density available, resulting in the potential for the technology to be scaled down to microscales ( $\mathrm{Fu}$ et al. 2012). One researcher developed a SMA actuated microgripper with three degrees of freedom and was capable of positioning the gripper jaws along the $\mathrm{x}$ and $\mathrm{y}$ axis (Abuzaiter et al. 2016). The structure consisted of three bimorph SMA sections. The first was connected to a base of the gripper and a strip of SMA material was able control the bending of the remaining structure along the x-axis. The second element, connected to the first, was another strip of SMA material which enabled the final section to be moved along the y-axis. The final section, the gripper itself, is made up of two SMA elements creating a cantilever-type gripper structure. These elements are able to flex and result in opening and closing of the gripper jaw and grasping hold of an object. Each SMA strip is controlled by independent circuits that conduct a current through each strip creating heat and subsequently flex (Abuzaiter et al. 2016). Experiments conducted trials using different thicknesses of SMA and silicon dioxide materials of the bimorph strip to achieve the greatest displacement (Abuzaiter et al. 2016). The maximum displacement of the first and second sections of the device reached $7.1 \mathrm{~mm}$ (Abuzaiter et al. 2016). The system was practically trialled and successfully manipulated a small object. Limitations of the developed microgripper included a time delay of approximately $10 \mathrm{~s}$ which occurred when actuating the bimorph strips. Furthermore there is a hysteresis issue when heating and cooling each strip (Abuzaiter et al. 2016). Another developed microgripper had an SMA actuator that was fabricated using nickel titanium material with silicon as presented in Lin et al. (2009). The materials were configured into a spring structure to produce a large jaw size of $120 \mu \mathrm{m}$. The springs were connected between a solid structure and to the middle section of cantilever arms. Using the same methods as previous reports, heat was applied to the SMA nickel titanium springs by supplying an electrical current which caused the springs to expand, resulting in the closure of gripper jaws (Lin et al. 2009). The silicon springs were put under tension and once the current supplied to the SMA springs is removed, the silicon springs caused the gripper jaws to open. This report stated that the advantages of using SMA actuators are that they supply high gripping forces, precision and response times (Lin et al. 2009). This last statement contradicts other reports that have stated slow actuator response times. However, this report has not stated the expected time delay of the developed microgripper. Researchers have also investigated the use of SMAs in the form of wire (Kyung et al. 2008; Jia and Xu 2013). This has been accomplished by creating a monolithic flexible hinge microgripper structure and utilizing SMA wires connected to the base. The gripper arms of the structure open and close the jaws as the temperature of the wire is altered (Kyung et al. 2008; Jia and $\mathrm{Xu}$ 2013). Another method utilizing SMA wires produced a cantilever type structure which was actuated by the wires (Raparelli et al. 2018). The research developed a gripping arm to have several staggered sections which were used to connect each separate length of SMA wire. This gripper was developed with this feature to produce a large jaw gap change. Another SMA wire actuated gripper was developed and manufactured (Wagner et al. 2008). The structure was manufactured out of silicon whilst a $50 \mu \mathrm{m}$ diameter SMA wire was utilized to close the jaws. The design of the structure used a four-bar mechanism, this parallelogram linkage structure ensures a parallel movement of the gripper tips (Wagner et al. 2008). Due to the small dimensions required for the microgripper it is not desirable to use physical hinges for the mechanisms (Wagner et al. 2008). Therefore, the gripper structure was initially developed with flexible hinges, however in the finite element model it could be noted that the majority of the structure had no applied stresses and a vast amount of stress were produced at the hinges. It was stated that this was not preferred and to utilize the material, it would be ideal to ensure that the stresses were dissipated throughout the entire structure (Wagner et al. 2008). To achieve this, the structure was redesigned, and the flexible hinges were removed. Instead, the four bars of the structure were reduced in width to produce four thin beams, twice as thick as the original hinges (Wagner et al. 2008). After completing another finite element test on the amended structure, it displayed that the stresses were now distributed throughout the thin beams. This method increases the durability of the structure. The design of microgripper was theoretically able to produce a large jaw displacement range, however the SMA wires that were experimentally used were not the preferred choice and hence produced less force than required whilst actuating (Wagner et al. 2008). This inevitably lead to a smaller jaw tip displacement that expected. However, there are also various limitations related to this technology particularly when using Nickel-Titanium material for its fabrication. These limitations include inefficient energy usage, slow response, high heat during operation and hysteresis and fatigue issues (Choudhary and Kaur 2016; Nemat-Nasser and Guo 2006; Yang et al. 2017; Rubio et al. 2009). Another limitation of this system is that the response given by the material is often unpredictable, which often 
leads to the actuator producing unknown positions whilst between the open and closed states (Fu et al. 2012).

\section{Robotic actuators in medical industry}

\subsection{Medical robotic systems}

Surgical robots for use within the medical industry has been thoroughly reseachered over the past few decades. Extensive research has been conducted into use of various types of surgical robots along with medical tools and actuators associated with the system. An increasing amount of research has been conducted into mechanical medical grippers, particularly with regards to minimally invasive surgery (MIS) and the need to manipulate delicate parts of the body such as blood vessels which have a diameter of less than $1 \mathrm{~mm}$. Medical microgrippers have been produced because of this and are particularly accurate and precise due to the medical nature. The majority of surgical robots are non-autonomous and currently require a surgeon to control the tools of the system. Robotic systems used for MIS comprise of a set of tools, often grippers, and a vision system which is controlled from a console situated away from the patient. Surgical robots have been developed in order aid surgeons during surgery and to reduce the amount of trauma induced to a patient. In 1995, a system called Zeus was developed which held various tools for an operation and was capable of mimicking the controls of the surgeon whilst increasing accuracy by reducing the surgeon's tremors and converting the surgeon's motions into small precise movements within the patient (Beasley 2012). One of the most commercially available robotic surgery systems is the Da Vinci system which was first available in the year 2000. This system contains three to four flexible arms that are used to control multiple types of tools to be used for MIS. The tools often include grippers which have two degrees of freedom (Beasley 2012). One report researched into the force response from various tools used by the system. It was discovered that whilst the different tool arms exerted the same gripping force, different tools exerted a wide range of forces, declaring that appropriate tools must be selected throughout an operation process depending on the task required (Mucksavage et al. 2011). Another system named Telelap ALF-X, comprises of four arms and is similar to the Da Vinci system, but also includes a haptic feedback system with an accuracy of $35 \mathrm{~g}$ (Beasley 2012). The benefit of the feedback system is that the surgeon can approximately detect the amount of force being applied by the grippers of tools and hence prevent damage to the patient. The system has been successfully trialled on animals and stated to have reduced operating times compared to other systems (Beasley 2012; Stark et al. 2012). The Raven surgical robot is a system similar to above and contains two tool arms and the system has seven degrees of freedom (Lum et al. 2009). This report tested the system using various experiments, predomintly for the study of the network effect on the system. When compared to traditional surgery methods, the above stated surgical robots have a reduced field of vision as the surgeon often views the procedure using only one or two cameras, also the remote end-effector system reduces the degrees of freedom that the surgeon can manipulate (Beasley 2012; Gomes 2011; Dogangil et al. 2010; Kuo and Dai 2009). It was found in a study that a large amount of errors caused by surgeons during traditional surgery were related to applying excess force to a patients tissue (Jin et al. 2016; Tang et al. 2004). Due to this, force sensors are commonly researched to integrate with the surgical robots as presented in the Teleap ALF-X system. The above stated systems are all non-autonomous and require surgeon control. The idea of autonomous force control has been disregarded by many as the intended force required within a patient is often variable and hence unknown (Harada et al. 2011). It seems that fully automated surgical robots will still require further research to be capable of assisting with surgical procedures. They currently would not be suitable due to the primitive systems that provide haptic feedback. Assisted robotic tools are more likely to be used as a surgeon would be on hand to conduct and analysis the procedure.

\subsection{Types of grippers}

Traditional methods for surgical operations use various tools that are often classified into six groups, cutting, grasping, haemostatic forceps, retractors, clamps and implants (Jin et al. 2016). Several of these tools involve a form of gripper to hold an internal part of the body. Various gripper types have been developed depending on the medical requirement, whether it involves grasping layers of tissue to manoeuvre or blood vessels to prevent blood loss. The surface of gripper jaws is often either smooth faced or tooth faced depending on the desired task. It has been stated that tooth formation grasping tools can cause an uneven distribution of force along a layer of tissue and hence result in additional force being applied in certain locations, often causing damage (Jin et al. 2016). It is suggested that numerical simulations are performed to assess the force applied by the gripper to ensure a uniform force is applied. A report by Xu et al. (2009) presented a design of a cable-actuated medical gripper capable of reaching high $40 \mathrm{~N}$ gripping force whilst also producing a wide jaw angle (Xu et al. 2009). These successes were reached by producing a hinge comprised of two slopes, one steep slope to produce the large gripping force, while the shallow slope ensured that the jaw can reach the wide angle 
(Xu et al. 2009). The jaw faces of the gripper were designed with teeth structures to increase the gripping force that could be applied. This type of design is advantages when attempting to grasp various objects with different sizes with different forces.

\subsection{Transmission systems}

Different forms of transmission systems have been studied for use in surgical robotic systems between controller and gripper, such transmission systems use include cable, fluid, smart material and magnetic. Each of these types have been stated to have multiple advantages and disadvantages with continuing research being conducted for each. Cable-actuated systems are capable of producing high gripping force however they often involve complicated and expensive fabrication processes, hysteresis issues and a short lifespan of ten surgical procedures due to the repetitive bending of the system (Le et al. 2016). Fluid-actuated transmission systems are able to supply a high force particularly at microscale and also achieve large bending angles, on the other hand they also involve a complicated system, require a high power supply and have hysteresis issues (Le et al. 2016). Another form of actuator uses shape memory alloys which are capable of applying a large force and displacement, but also can apply the force along three axis (Le et al. 2016). This form of transmission however has a low frequency response to controls and is stated to have issues with accurate control (Le et al. 2016). The final actuator type reviewed uses a magnetic system which is capable of transferring motion wirelessly, however hysteresis and linearity issues do occur (Le et al. 2016). Therefore, it is not clear what the most recommended system to utilize is when producing a tele-operated surgical robotic system as each transmission method has various advantages and disadvantages associated to them. It is recommended that further research should be conducted to overcome or alleviate the disadvantages of the selected system (Le et al. 2016). Despite the amount of research studied in this area, it is important to note that these types of grippers are designed to handle biological material that are relatively large compared to microscale objects as discussed in previous chapters. For example, the smallest diameter of a human arteries is around $100 \mu \mathrm{m}$, which is stated as the maximum limit of microscale objects.

\subsection{Magnetic guiding systems}

Another method of object manipulation involves the use of a magnetic field to guide non-magnetic flexible wire by attaching a magnetic tip to the wire's end. This method has been recently studied for use in the medical industry where minimally invasive surgery is become ever more researched. The method is used to accurately position a wire whilst inside of a patient. One paper studied into externally manipulating a wire whilst inside of a patient's veins (Yeow et al. 2016). The system developed can adjust the angle of the flexible wire by using a robotically controlled magnetic field. As the flexible wire itself was nonmagnetic, the tip of the wire was coated in a ferro-magnetic material and hence could be controlled by the magnetic field (Yeow et al. 2016). The magnetic field itself was produced by applying a current to several electromagnetic coils distributed around the manipulation zone (Yeow et al. 2016). The magnetic tip of the wire was able to be adjusted by altering the voltage applied to the coils (Yeow et al. 2016). The system was tested by measuring the deflection of the wire tip and comparing it to the input movement expected (Yeow et al. 2016). The measured deflection angle was found to be $20^{\circ}$, resulting in a deflection displacement of around $7 \mathrm{~mm}$. One of the limitations with the system was that the size of the manipulation zone and the deflection angle were both limited by the applied magnetic field. It was stated that the flux density of their system was $20 \mathrm{mT}$, whereas other researchers used values around $100 \mathrm{mT}$ (Yeow et al. 2016). By increasing the magnetic flux density, they would be able to increase the size of the work zone and the deflection of the wire (Yeow et al. 2016). This method is capable of adjusting the position of a wire on a fine scale. This type of system has the potential to be utilized in order to manipulate certain micro-objects e.g. wires. However, this research paper does not state the precision of the system and therefore may not be accurate enough to be able to manipulate micro-objects to a desired location as indicated. Another area of the medical industry where this form of technology has been researched for is related to the internal delivery of drugs to a specific location inside of a patients' body (Shen et al. 2015). The research developed an electromagnetic field which was used to alter the position and alignment of microcapsules which contained both the drug required, but also iron particles which enabled the capsule to be positioned by the magnetic field (Shen et al. 2015). The electromagnetic field was created by using a system containing Helmoholz and Maxwell coil pairs which produce a uniform and gradient magnetic field respectively. This system successfully enabled to position the magnetic particles (Shen et al. 2015). The design of the drug delivery system had approximately a $21 \mathrm{~mm}^{3}$ manipulation zone due to the size of the coils, this system design could become unsuitable if larger components are required to be manipulated (Shen et al. 2015). The use of permanent magnets as a guiding system has also been researched for the medical industry (Schiemann et al. 2004). A guiding zone was reported by placing two magnets parallel to each other and on either side of the patient and were capable of producing a $0.1 \mathrm{~T}$ 
magnetic field (Schiemann et al. 2004). The magnets were able to be rotated and re-positioned to orientate the magnetic tip of the flexible wire. The tip of the wire comprised of a neodymium iron boron magnet due to its highly magnetic properties (Schiemann et al. 2004). The magnetic system was successfully able to rotate the tip of the wire in any direction. Although the angle of the tip was controlled using non-contact external magnetic fields, the progression of the wire into the patient is carried out manually. The magnetic field rotated the tip of the wire by an angle of $90^{\circ}$ and it was calculated that a force of $0.56 \mathrm{~g}$ would be applied by the tip onto the internal walls of the patient (Schiemann et al. 2004). The paper concluded that the developed system was capable of accurate positioning of the magnetic tip of the wire whilst inside of an artificial test chambers, however the accuracy of the positioning of the tip was not specified. A complex system comprised of a series of eight electromagnets has also been developed (Kummer et al. 2010). The configuration of the system was capable of producing a non-uniform magnetic field throughout the manipulation zone (Kummer et al. 2010). The system, named OctoMag, was designed to control microrobots inside of a patient, whilst also to be used to manipulate a magnetic tipped wire, similar to the systems presented previously in this section. It is capable of manipulating an isolated microrobot by five degrees of freedom, not only its orientation, but also its position within the manipulation zone (Kummer et al. 2010). It utilizes a vision system as a form of feedback, to monitor the accurate location and orientation of the magnetic object. It was stated in the report that the Octomag system had the potential to be reduced in size and could be used for micromanipulation under a microscope (Kummer et al. 2010). During experimentation conducted with the microrobots it was said stated that a variation of $29.77 \mu \mathrm{m}$ was present. Another successful magnetic navigation system has been described in Chun et al. (2007). The system includes two permanent magnets situated on either side of the patient. The magnets were able to create a $0.08 \mathrm{~T}$ uniform field across the patient and steer a tethered wire with a magnetised tip through the body (Chun et al. 2007). In the paper, it stated that different tip structures were trialled which included various number of magnets along the tip. It was concluded that the constructed tip which comprised of four magnets was the most controllable tether and therefore the most successful during tests (Chun et al. 2007).

\subsection{Probe technology}

The use of probe structures has also been studied to manipulation micro-objects. Many different technologies have been studied such as optical, mechanical, magnetic and electrostatic (Kawamoto 2009). The method of using an electrostatic force for manipulation has been successfully achieved by many researchers and is often intended for the manipulation of micro-particles such as biological cells and micro-mechanical and micro-electronic objects. One report concluded that tools for micromanipulation such as probes are preferred due to their simple design, whilst microgrippers involve a more complex design and are often delicate and expensive (Power and Yang 2015). Electrostatic probes are often capable of adhering to particles between the sizes of $10 \mu \mathrm{m}$ to $1 \mathrm{~mm}$ (Kawamoto 2009; Takahashi et al. 2001). It has been stated that use of the probes are often limited to the manipulation of small spheres within this size as the adhesion forces, including van der Waals, electrostatic and liquid bridge forces are often larger than the gravitational forces that oppose them (Konno et al. 2005; Masuda et al. 2006; Saito et al. 2003). It is less common to be able to attract larger metallic micro objects as the electrostatic attraction is often weaker than the gravitational forces applied to it (Konno et al. 2005). It is stated that these adhesion forces occur between, the substrate and the particle and also the probe and the particle (Konno et al. 2005; Masuda et al. 2006). To ensure that the probe is capable of picking up the particle, the adhesion force between particle and probe must be larger than the sum of adhesion forces between substrate and particle and the gravitational force applied to the particle (Konno et al. 2005). These forces are affected by the materials and shape of the probe, particle and substrate (Konno et al. 2005). The force between the probe and the particle is enhanced by applying a voltage to the probe which increases the electrostatic force available (Konno et al. 2005). It is this force that ensures that the particle can be manipulated by the probe. The fabrication of the probes is typically manufactured from tungsten wire with a diameter of approximately $100 \mu \mathrm{m}$. The wire is often polished and coated in an insulating material to avoid the probe from short circuiting. Researchers have stated that the fabrication and operation of the probe is simple (Kawamoto and Tsuji 2011). Many configurations of probes have been developed and often consist of one, two or three metallic cores where a voltage is applied to. From this, a non-uniform electrostatic field is formed around the probe and generates a Coulomb force that is capable of attracting both non-conductive and conductive micro-particles towards it (Kawamoto 2009). It was established that for conductive micro-particles, the resistivity of the microparticle material must be between $10^{7}$ and $10^{9} \Omega \mathrm{cm}$ while the voltage of the probe was $10 \mathrm{~V}$ (Kawamoto 2009). The probe is capable of releasing non-conductive particles by setting the voltage to zero (Kawamoto 2009). The same cannot be done for conductive particles as even after the voltage has reached zero the Coulomb adhesion force will 
still be present and will continue to attract the particle to the probe tip (Kawamoto 2009). The researchers investigated different elements of the probe and the particle to study what would influence the attraction forces of both. Such elements were the dimensions and voltage of the probe and dimensions and material of the micro-object. Even though that increasing the voltage increased the attraction forces, the voltage limit must be noted due to the insulated breakdown properties of the probe (Kawamoto 2009). The research results demonstrated that the duel-core probe, was capable of picking up non-conductive microparticles with diameters of 150-2000 $\mu \mathrm{m}$ and a weight of about 1-1000 $\mu \mathrm{g}$ (Kawamoto 2009). Another configuration of probe, with a duel-core and a staggered tip, was capable of manipulating similar sized particles, with diameters of $100-1000 \mu \mathrm{m}$ and a weight of 0.6-800 $\mu \mathrm{g}$ (Kawamoto 2009). The single tip probe configuration, which was coated in a gold layer was able to move much smaller particles, with diameters of 30-500 $\mu \mathrm{m}$ and a weight of 0.01-50 $\mu \mathrm{g}$ (Kawamoto 2009). The same researcher later demonstrated that the developed probe was able to pick up slightly conductive, non-spherical, lunar dust particles (Kawamoto and Tsuji 2011). The system was similar, if not identical to the probe developed in Kawamoto (2009). Another researcher carried out a similar electrostatic tip fabrication, but instead of using a tungsten wire they simply used a cantilever from an atomic force microscope due to it being an appropriate and repeatable shape and size (Denisyuk et al. 2014). This ensures that the experiment will be repeatable in the future. The experimentation of the cantilever probe was carried out on three different types of particles (Denisyuk et al. 2014). The particles were a mixture of spherical and octahedron in shape. During experimentation, it was noticed that the octahedron shaped particles could only be picked up while the probe was in contact with one of its vertices (Denisyuk et al. 2014). The researchers also produced a theoretical model of the manipulation of one of the particles. Using the model, they calculated that the probe was capable of attracting a particle while the distance between the probe tip and the particle was smaller than the diameter of the particle (Denisyuk et al. 2014). Another research that was conducted by previously was capable of manipulating 40-80 $\mu \mathrm{m}$ diameter gold spheres using a fine probe (Konno et al. 2005). This was accomplished by applying a 20-50 DC voltage to the probe (Konno et al. 2005). The spheres were then released by changing the voltage to zero. The researchers proved that their probe and system was capable of picking up the particle and also welding it to an additional particle by significantly increasing the voltage (Konno et al. 2005). As stated before, it was demonstrated that their developed probes were capable of manipulating micro-particles with a mass between 0.01 and $1000 \mu \mathrm{g}$
(Kawamoto 2009). The mass of the wire is within the stated values which implies that this method would be capable of manipulating a variety of wire materials and sizes.

\section{Summary}

The aim of this review was to research an array of previously designed and developed micromanipulation tools and discuss the most suitable technology in order to manipulate specific objects required for the assembly of $\mu$-wire. Robotic controlled micromanipulation tools such as previously mentioned microgrippers could be also be employed in order to achieve the high level of accuracy and repeatability required for assembly at this scale. The review has compared different micromanipulation tools currently available in order to manipulate micro-objects and specifies the most preferable solutions. A large variety of different micromanipulation techniques involving contact and contactless technologies have been summarised and evaluated. The majority of this review has focused on microgripper technologies, comparing the advantages and disadvantages of both their structure and actuator types as these are the fundamental components of determining the most suitable design for micromanipulation. After analysing, it became clear that high precision and repeatability were the most desirable characteristics of the manipulation tool. Robotic tools developed for the medical industry contain state-of-the-art technology, however they may not be suitable for this specific micromanipulation task due to the comparatively large scale of the objects that they are intended to grasp. Another manipulation technology studied utilized magnetic fields in order to orientate magnetic or magnetic-tipped wires (Power and Yang 2015). This form of technology is useful for guiding a wire through an intended path, although the system itself could not change the position of the object and only align it with the magnetic field, therefore would not be suitable for positioning certain $\mu$-wire materials. Various technologies of probes were also studied, such as electrostatic; however, the system researched were only studied to have manipulated micro-objects that were near spherical in shape. The shape wire makes it more difficult to manipulate whilst using these technologies.

\section{Conclusion}

From the previously stated various microgripper actuator types, shape memory alloys actuated microgrippers previously developed have displayed large jaw displacement and high gripping force compared to other types (Kyung et al. 2008). The presented disadvantages such as high 
hysteresis error, large energy usage and a slow response time were agreed to not greatly impact the manipulation process of the given task (Yang et al. 2017). It seemed that this technology was the most suitable to manipulate $\mu$-wire. The reviewed literature failed to include a suitable microgripper design that would be capable of grasping and positioning a micro-sized object such as $\mu$-wire and larger sized objects. It is deemed that a solution to this problem must be addressed. Additionally, many microgrippers are found to be inaccurate, often due to the fabrication process which cause an undesired asymmetrical structure of microgripper (Liang et al. 2018). A solution to this issue has been previously presented while utilizing piezoelectric materials as a form of actuator (Liang et al. 2018), however, alternative actuation methods are being researched and there is potential for these to achieve a higher increase in grasp accuracy when used with specific microgripper designs. The microgripper design will need to ensure that a large range of objects can be grasped ranging from sizes of the $\mu$-wire to different components such as PCBs. The developed microgripper must be versatile enough to assist with the manipulation of other micro-objects including those in other alternative industrial sectors.

Acknowledgements The authors would like to acknowledge the support of the Future Manufacturing Research Institute, College of Engineering, Swansea University and Advanced Sustainable Manufacturing Technologies (ASTUTE 2022) project, which is partly funded from the EU's European Regional Development Fund through the Welsh European Funding Office, in enabling the research upon which this paper is based. Further information on ASTUTE can be found at www.astutewales.com.

Open Access This article is licensed under a Creative Commons Attribution 4.0 International License, which permits use, sharing, adaptation, distribution and reproduction in any medium or format, as long as you give appropriate credit to the original author(s) and the source, provide a link to the Creative Commons licence, and indicate if changes were made. The images or other third party material in this article are included in the article's Creative Commons licence, unless indicated otherwise in a credit line to the material. If material is not included in the article's Creative Commons licence and your intended use is not permitted by statutory regulation or exceeds the permitted use, you will need to obtain permission directly from the copyright holder. To view a copy of this licence, visit http://creativecommons. org/licenses/by/4.0/.

\section{References}

Abuzaiter A, Nafea M, Mohamed Ali MS (2016) Development of a shape-memory-alloy micromanipulator based on integrated bimorph microactuators. Mechatronics 38:16-28

Adriaens HJMTA, De Koning WL, Banning R (2000) Modeling piezoelectric actuators. IEEE/ASME Trans Mechatron 5(4):331-341

Beasley RA (2012) Medical robots: current systems and research directions. J Robot 2012:1-14
Beyeler F, Neild A, Oberti S, Bell DJ, Sun Y, Dual J, Nelson BJ (2007) Monolithically fabricated microgripper with integrated force sensor for manipulating microobjects and biological cells aligned in an ultrasonic field. J Microelectromech Syst 16(1):7-15

Bordatchev EV, Nikumb SK (2003) Microgripper: design, finite element analysis and laser microfabrication. Comput Soc $4((\mathrm{~L})): 1-5$

Cauchi M, Grech I, Mallia B, Mollicone P, Sammut N (2018) Analytical, numerical and experimental study of a horizontal electrothermal MEMS Microgripper for the deformability characterisation of human red blood cells. Micromachines 9(3):108

Chen T, Chen L, Sun L, Li X (2009) Design and fabrication of a fourarm-structure MEMS gripper. IEEE Trans Ind Electron 56(4):996-1004

Choudhary N, Kaur D (2016) Shape memory alloy thin films and heterostructures for MEMS applications: a review. Sens Actuators A Phys 242:162-181

Chronis N, Chronis N, Lee LP (2005) Electrothermally activated SU8 microgripper for single cell manipulation in solution electrothermally activated SU-8 microgripper for single cell manipulation in solution. Microelectromech Syst 14(August):857-863

Chun JKR, Ernst S, Matthews S, Schmidt B, Bansch D, Boczor S, Ujeyl A, Antz M, Ouyang F, Kuck KH (2007) Remotecontrolled catheter ablation of accessory pathways: results from the magnetic laboratory. Eur Heart J 28(2):190-195

Conway NJ, Kim S-G (2004) Large-strain, piezoelectric, in-plane micro-actuator. In: 17th IEEE international conference micro electro mechanics system. Maastricht MEMS 2004 Technical Digest, vol 2, issue 1

Denisyuk AI, Komissarenko FE, Mukhin IS (2014) Electrostatic pickand-place micro/nanomanipulation under the electron beam. Microelectron Eng 121:15-18

Dochshanov A, Verotti M, Belfiore NP (2017) A comprehensive survey on microgrippers design: operational strategy. J Mech Des 139(7):70801

Dogangil G, Davies BL, Rodriguez F, Baena Y (2010) A review of medical robotics for minimally invasive soft tissue surgery. Proc Inst Mech Eng Part H J Eng Med 224(5):653-679

Du H, Su C, Lim MK, Jin WL (1999) Micromachined thermallydriven gripper: a numerical and experimental study. Smart Mater Struct 8(5):616-622

Duc TC, Creemer JF, Sarro PM (2006) Lateral nano-Newton forcesensing piezoresistive cantilever for microparticle handling. J Micromech Microeng 16(6):S102-S106

Elsen R, Bharadwaj K, Ramesh T (2019) A parametric study on electro thermally actuated compliant microgripper. In: SAE Technical Paper 2019-28-0032. https://doi.org/10.4271/201928-0032

El-Sayed AM, Abo-Ismail A, El-Melegy MT, Hamzaid NA, Osman NA (2013) Development of a microgripper using piezoelectric bimorphs. Sensors (Switzerland) 13(5):5826-5840

Fu RYQ, Luo JK, Flewitt AJ, Milne WI (2012) Smart microgrippers for bioMEMS applications. MEMS Biomed Appl 291-336

Gaafar E, Zarog M (2017) A low-stress and low temperature gradient microgripper for biomedical applications. Microsyst Technol 23(12):5415-5422

Giouroudi I, Hötzendorfer H, Kosel J, Andrijasevic D, Brenner W (2008) Development of a microgripping system for handling of microcomponents. Precis Eng 32(2):148-152

Gomes P (2011) Surgical robotics: reviewing the past, analysing the present, imagining the future. Robot Comput Integr Manuf 27(2):261-266

Grossard M, Rotinat-Libersa C, Chaillet N, Boukallel M (2009) Mechanical and control-oriented design of a monolithic 
piezoelectric microgripper using a new topological optimization method. IEEE/ASME Trans Mechatron 14(1):32-45

Haddab Y, Chaillet N, Bourjault A (2000) A microgripper using smart piezoelectric actuators. In: Proceedings of 2000 IEEE/RSJ international conference on intelligent robots and systems (IROS 2000), Takamatsu, Japan, pp 659-664

Harada K, Minakawa Y, Baek Y, Kozuka Y, Sora S, Morita A, Sugita N, Mitsuishi M (2011) Microsurgical skill assessment: toward skill-based surgical robotic control. In: Proceedings of annual international conference IEEE engineering medical biological society EMBS, vol 2011. pp 6700-6703

Jain RK, Majumder S, Ghosh B, Saha S (2015) Design and manufacturing of mobile micro manipulation system with a compliant piezoelectric actuator based micro gripper. J Manuf Syst 35:76-91

Jia Y, Xu Q (2013) MEMS microgripper actuators and sensors: the state-of-the-art survey. Recent Patents Mech Eng 6(2):132-142

Jin ZM, Zheng J, Li W, Zhou ZR (2016) Tribology of medical devices. Biosurface Biotribol 2(4):173-192

Kalaiarasi AR, Thilagar SH (2012) Design and modeling of electrostatically actuated microgripper. In: Proceedings of 2012 8th IEEE/ASME international conference mechatronics embedded system applications MESA 2012, pp 7-11

Kawamoto H (2009) Manipulation of single particles by utilizing electrostatic force. J Electrostat 67(6):850-861

Kawamoto H, Tsuji K (2011) Manipulation of small particles utilizing electrostatic force. Adv Powder Technol 22(5):602-607

Keoschkerjan R, Wurmus H (2002) A novel microgripper with parallel movement of gripping arms. In: 8th international conference on new actuators, ACTUATOR 2002, Bremen, German, pp 321-324

Kim DH, Lee MG, Kim B, Sun Y (2005) A superelastic alloy microgripper with embedded electromagnetic actuators and piezoelectric force sensors: a numerical and experimental study. Smart Mater Struct 14(6):1265-1272

Kolahdoozan M, Rouhani Esfahani A, Hassani M (2017) Experimental and numerical investigation of the arms displacement in a new electrothermal MEMS actuator. Int $\mathbf{J}$ Adv Des Manuf Technol 10(2)

Konno T, Kobayashi M, Egashira M, Shinya N (2005) Manipulation and welding of metal spheres above $10 \mu \mathrm{m}$ using needle-like probe. Sci Technol Adv Mater 6(5):529-534

Kummer MP, Abbott JJ, Kratochvil BE, Borer R, Sengul A, Nelson BJ (2010) Octomag: an electromagnetic system for 5-DOF wireless micromanipulation. IEEE Trans Robot 26(6):1006-1017

Kuo C-H, Dai JS (2009) Robotics for minimally invasive surgery: a historical review from the perspective of kinematics. In: International symposium on history of machines and mechanisms, Springer, pp 337-354

Kyung JH, Ko BG, Ha YH, Chung GJ (2008) Design of a microgripper for micromanipulation of microcomponents using SMA wires and flexible hinges. Sens Actuators A Phys 141(1):144-150

Le HM, Do TN, Phee SJ (2016) A survey on actuators-driven surgical robots. Sens Actuators A Phys 247:323-354

Liang C, Wang F, Shi B, Huo Z, Zhou K, Tian Y, Zhang D (2018) Design and control of a novel asymmetrical piezoelectric actuated microgripper for micromanipulation. Sens Actuators A Phys 269:227-237

Liaw HC, Shirinzadeh B, Smith J (2008) Sliding-mode enhanced adaptive motion tracking control of piezoelectric actuation systems for micro/nano manipulation. IEEE Trans Control Syst Technol 16(4):826-833
Lin CM, Fan CH, Lan CC (2009) A shape memory alloy actuated microgripper with wide handling ranges. IEEE/ASME Int Conf Adv Intell Mechatron, AIM, pp 12-17

Long Z, Zhang J, Liu Y, Han C, Li Y, Li Z (2017) Dynamics modeling and residual vibration control of a piezoelectric gripper during wire bonding. IEEE Trans Compon Packag Manuf Technol 7(12):2045-2056

Lum MJH, Friedman DCW, Sankaranarayanan G, King H, Fodero K, Leuschke R, Hannaford B, Rosen J, Sinanan MN (2009) The RAVEN: design and validation of a telesurgery system. Int $\mathbf{J}$ Robot Res 28(9):1183-1197

Masuda H, Gotoh K, Higashitani K, Shuji M (2006) Adhesive force of a single particle. In: Powder technology handbook. pp 157-170. https://doi.org/10.1201/9781439831885

Mucksavage P, Kerbl DC, Pick DL, Lee JY, McDougall EM, Louie MK (2011) Differences in grip forces among various robotic instruments and da vinci surgical platforms. J Endourol 25(3):523-528

Munasinghe KC, Bowatta BGCT, Abayarathne HYR, Kumararathna $\mathrm{N}$, Maduwantha LKAH, Arachchige NMP, Amarasinghe YWR (2016) New MEMS based micro gripper using SMA for micro level object manipulation and assembling. In: 2nd international Moratuwa engineering research conference MERCon. pp. 36-41

Nah SK, Zhong ZW (2007) A microgripper using piezoelectric actuation for micro-object manipulation. Sens Actuators A Phys 133(1):218-224

Nemat-Nasser S, Guo WG (2006) Superelastic and cyclic response of NiTi SMA at various strain rates and temperatures. Mech Mater 38(5-6):463-474

Nikoobin A, Niaki MH (2012) Deriving and analyzing the effective parameters in microgrippers performance. Sci Iran 19(6):1554-1563

Power M, Yang GZ (2015) Direct laser written passive micromanipulator end-effector for compliant object manipulation. In: IEEE international conference on intelligent robots and systems (IROS), pp 790-797

Qin Y, Tian Y, Zhang D, Shirinzadeh B, Fatikow S (2013) A novel direct inverse modeling approach for hysteresis compensation of piezoelectric actuator in feedforward applications. IEEE/ASME Trans Mechatron 18(3):981-989

Qingsong X (2015) Design of asymmetric flexible microgripper mechanism based on flexure hinges. Adv Mech Eng 7(6):1-8

Qu J, Zhang W, Jung A, Silva-Da Cruz S, Liu X (2017) Microscale compression and shear testing of soft materials using an MEMS Microgripper with two-axis actuators and force sensors. IEEE Trans Autom Sci Eng 14(2):834-843

Rakotondrabe M, Ivan IA (2010) Principle, characterization and control of a new hybrid thermo-piezoelectric microactuator. In: Proceedings of IEEE international conference robotics automation. pp 1580-1585

Rakotondrabe M, Ivan IA (2011) Development and force/position control of a new hybrid thermo-piezoelectric microgripper dedicated to micromanipulation tasks. IEEE Trans Autom Sci Eng 8(4):824-834

Raparelli T, Zobel PB, Durante F (2018) A proposed methodology for the development of microgrippers: an application to a silicon device actuated by shape memory alloy. Int J Mech Eng Technol 9(2):235-249

Rubio WM, Silva ECN, Bordatchev EV, Zeman MJF (2009) Topology optimized design, microfabrication and characterization of electro-thermally driven microgripper. J Intell Mater Syst Struct 20(6):669-681

Ruiz D, Díaz-Molina A, Sigmund O, Donoso A, Bellido JC, SánchezRojas JL (2018) Optimal design of robust piezoelectric unimorph microgrippers. Appl Math Model 55:1-12 
Saito S, Himeno H, Takahashi K (2003) Electrostatic detachment of an adhering particle from a micromanipulated probe. J Appl Phys 93(4):2219-2224

Schiemann M, Killmann R, Kleen M, Abolmaali N, Finney J, Vogl TJ (2004) Vascular guide wire navigation with a magnetic guidance system: experimental results in a phantom. Radiology 232(2):475-481

Shen S, Song S, Zhu J, Meng MQ-H, Li J, Ren H (2015) Preliminary design towards a magnetic actuated drug delivery system. In: 2015 IEEE 7th international conference on cybernetics and intelligent systems (CIS) and IEEE conference on robotics, automation and mechatronics (RAM), pp 245-249

Shi Q, Yu Z, Wang H, Sun T, Huang Q, Fukuda T (2018) Development of a highly compact microgripper capable of online calibration for multi-sized microobject manipulation. IEEE Trans Nanotechnol 17(4):1

Somà A, Iamoni S, Voicu R, Müller R, Al-Zandi MHM, Wang C (2018) Design and experimental testing of an electro-thermal microgripper for cell manipulation. Microsyst Technol 24(2):1053-1060

Stark M, Benhidjeb T, Gidaro S, Morales ER (2012) The future of telesurgery: a universal system with haptic sensation. J Turk Ger Gynecol Assoc 2012(1):74-76

Suzuki Y (1994) Fabrication and evaluation of flexible microgripper. Jpn Soc Appl Phys 33(4):2107-2112

Takahashi K, Kajihara H, Urago M, Saito S, Mochimaru Y, Onzawa $\mathrm{T}$ (2001) Voltage required to detach an adhered particle by Coulomb interaction for micromanipulation. J Appl Phys 90(1):432-437

Tang B, Hanna GB, Joice P, Cuschieri A (2004) Identification and categorization of technical errors by Observational Clinical Human Reliability Assessment (OCHRA) during laparoscopic cholecystectomy. Arch Surg 139(11):1215-1220

Verotti M, Dochshanov A, Belfiore NP (2017) A comprehensive survey on microgrippers design: mechanical structure. J Mech Des 139(6):60801

Wagner MFX, Nayan N, Ramamurty U (2008) Healing of fatigue damage in NiTi shape memory alloys. J Phys D Appl Phys 41(18): 185408

Wang DH, Yang Q, Dong HM (2013a) A monolithic compliant piezoelectric-driven microgripper: design, modeling, and testing. IEEE/ASME Trans Mechatron 18(1):138-147

Wang Y, Ma G, Yang C, Yin W (2013b) Robotics system used for gripping wires with dozens of microns based on stereo light microscope. In: 2013 IEEE International Conference on Information and Automation (ICIA)

Wang F, Liang C, Tian Y, Zhao X, Zhang D (2015) Design of a piezoelectric-actuated microgripper with a three-stage flexure- based amplification. IEEE/ASME Trans Mechatron 20(5):2205-2213

Wu Z, Xu Q (2018) Survey on recent designs of compliant micro-/nano-positioning stages. Actuators 7(1):5

Xu Q (2014a) Design and testing of a novel multi-stroke micropositioning system with variable resolutions. Rev Sci Instrum 85(2):025002

Xu Q (2014b) Design and smooth position/force switching control of a miniature gripper for automated microhandling. IEEE Tans Ind Inform 10(2):1023-1032

Xu Q (2018) Design, modeling, and control of a constant-force microgripper. In: Micromachines for biological micromanipulation. Springer International Publishing AG, pp 119-143

Xu K, Goldman RE, Ding J, Allen PK, Fowler DL, Simaan N (2009) System design of an insertable robotic effector platform for Single Port Access (SPA) surgery. In: 2009 IEEE/RSJ international conference intelligence robotics systems IROS. pp 5546-5552

Yang S, Xu Q (2017) A review on actuation and sensing techniques for MEMS-based microgrippers. J Microbiol Robot 13(1-4):1-14

Yang YL, Wei YD, Lou JQ, Fu L, Fang S (2017) Design and control of a multi-DOF micromanipulator dedicated to multiscale micromanipulation. Smart Mater Struct 26(11):115016

Yeow BS, Sun J, Ho J, Ren H (2016) A magnetically actuated guidewire steering system towards arteriovenous fistula angioplasty procedures. In: 2016 IEEE international conference real-time computational robotics RCAR 2016. pp 1-6

Yuan G, Yuan W, Hao Y, Li X, Chang H (2015) A microgripper with a post-assembly self-locking mechanism. Sensors (Switzerland) 15(8):20140-20151

Zhang R, Chu JK, Chen ZP (2011) A novel SU-8 electrothermal microgripper based on type synthesis of kinematic chain method. In: Proceedings of 16th international conference (Transducers) of Solid-state sensors, actuators and microsystems, pp 466-469

Zhang R, Chu J, Wang H, Chen Z (2013) A multipurpose electrothermal microgripper for biological micro-manipulation. Microsyst Technol 19(1):89-97

Zhong ZW, Yeong CK (2006) Development of a gripper using SMA wire. Sens Actuators, A Phys 126(2):375-381

Zubir MNM, Shirinzadeh B, Tian Y (2009) Development of a novel flexure-based microgripper for high precision micro-object manipulation. Sens Actuators A Phys 150(2):257-266

Publisher's Note Springer Nature remains neutral with regard to jurisdictional claims in published maps and institutional affiliations. 